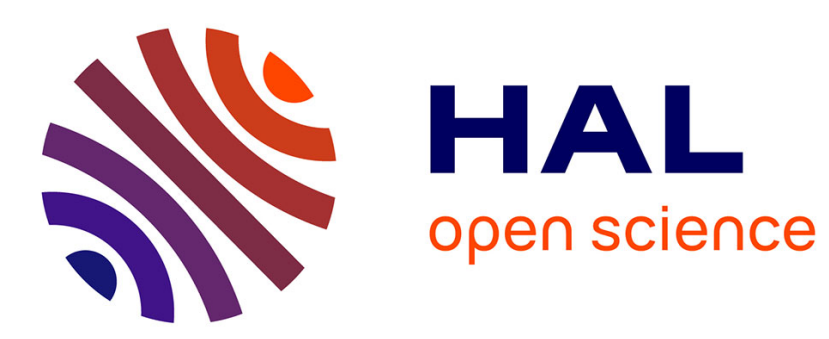

\title{
Mood and gradability: an investigation of the subjunctive mood in Spanish
}

\author{
Elisabeth Villalta
}

\section{To cite this version:}

Elisabeth Villalta. Mood and gradability: an investigation of the subjunctive mood in Spanish. Linguistics and Philosophy, 2009, 31 (4), pp.467-522. 10.1007/s10988-008-9046-x . hal-00478453

\section{HAL Id: hal-00478453 \\ https://hal.science/hal-00478453}

Submitted on 30 Apr 2010

HAL is a multi-disciplinary open access archive for the deposit and dissemination of scientific research documents, whether they are published or not. The documents may come from teaching and research institutions in France or abroad, or from public or private research centers.
L'archive ouverte pluridisciplinaire HAL, est destinée au dépôt et à la diffusion de documents scientifiques de niveau recherche, publiés ou non, émanant des établissements d'enseignement et de recherche français ou étrangers, des laboratoires publics ou privés. 


\title{
Mood and Gradability: An Investigation of the Subjunctive Mood in Spanish
}

\begin{abstract}
In Spanish (and other Romance languages) certain predicates select the subjunctive mood in the embedded clause, while others select the indicative mood. In this paper, I present a new analysis for the predicates that select the subjunctive mood in Spanish that is based on a semantics of comparison. The main generalization proposed here is the following: in Spanish, a predicate selects the subjunctive mood in its embedded proposition if the proposition is compared to its contextual alternatives on a scale introduced by the predicate. In this proposal, predicates that select the subjunctive mood are thus analyzed as gradable predicates. Furthermore, the subjunctive mood morpheme is claimed to make a semantic contribution, namely to evaluate the contextual alternatives that are compared by the predicate. In comparing this proposal to other approaches, I show that it can more straightforwardly account for a number of properties of these predicates (entailment relations, practical inferences, and contexts with more than two alternatives). New empirical evidence for two crucial properties of the predicates that select the subjunctive mood is provided: these predicates are focus sensitive and they are gradable, two properties that follow directly from the proposal developed here. In the vast literature on mood, the link between the appearance of the subjunctive mood and these important properties has never been made before.
\end{abstract}




\section{Introduction}

In Spanish (and other Romance languages) certain predicates select the subjunctive mood in the embedded clause, while others select the indicative mood. In this paper, I develop a new analysis for the predicates that select the subjunctive mood in Spanish. Starting out with Heim=s (1992) semantics for propositional attitude predicates, I develop an analysis that is based on a semantics of comparison. The main generalization proposed here is the following: in Spanish, a predicate selects the subjunctive mood in its embedded proposition if the proposition is compared to its contextual alternatives on a scale introduced by the predicate. In this proposal, predicates that select the subjunctive mood are thus analyzed as gradable predicates.

The following important question will also be addressed: what role does the subjunctive mood play in the semantic composition of the sentence? The investigation of what the subjunctive mood contributes to the meaning composition provides a first step towards a better understanding of why subjunctive verb forms require special semantic licensing conditions and why they are obligatory in certain contexts. I will argue that the licensing conditions of subjunctive clauses can be explained in a system in which, next to the ordinary semantic value, we also compute an alternative semantic value of the sentence (cf. Rooth 1985). The view that the semantic component consists of two semantic values rather than just the ordinary semantic value has proven to be very fruitful in various areas. In Rooth (1985) it was introduced to account for focus phenomena and focus sensitive operators such as only, but later also employed by Krifka (1995) for the licensing of negative polarity items. Most recently, Beck (2006, to appear) argues that this view can successfully be adopted for the analysis of a whole range of constructions and linguistic phenomena. I show here that this view is also fruitful for an explanation of the licensing conditions of the subjunctive mood.

Mood selection in Romance is of course too complex to be treated here in an exhaustive manner. This paper concentrates uniquely on the Spanish data and is limited to a discussion of the characteristics of the predicates that select the subjunctive mood. There are other semantic and pragmatic factors that may influence mood selection in Spanish (such as negation, interrogatives or conditionals) but these will not be discussed here.

The subjunctive mood in Romance languages has received considerable attention in traditional as well as in recent theoretical linguistic literature. The subjunctive mood has been related to notions such as Irrealis (Givón 1994), Non-assertion (Bolinger 1968, Terrell \& Hooper 1974, Panzeri 2002, 
2003, Schlenker 2005), Strong Intensionality (Farkas 1985, 1992), Non-Veridicality (Giannakidou 1997, 1998, 1999), Model Shift (Quer 1998), Modality (Giorgi \& Pianesi 1997, Portner 1992,1997), and many more. Most of these proposals have concentrated on characterizing the common properties of the contexts that trigger the subjunctive mood rather than spelling out an explicit semantics for the predicates that select the subjunctive mood. For reasons of space, I will not go into the details of these approaches here. ${ }^{1}$ I will limit myself to comparing my proposal to those approaches that present an explicit proposal for the semantics of these predicates, such as Heim (1992), von Fintel (1999) and Giorgi and Pianesi (1997). In particular, Giorgi and Piannesi (1997) propose that the licensing contexts for subjunctive mood can be characterized with Kratzer=s semantics for modality (cf. Kratzer 1977, 1981, 1999). I will argue that an approach which uses such a semantics for these predicates cannot account for a number of important properties (entailment relations, practical inferences, and contexts with more than two alternatives). To the contrary, the proposal developed here accommodates these properties in a straightforward way.

Finally, in this paper, new empirical evidence for two crucial properties of the predicates that select the subjunctive mood will be discussed: these predicates are focus sensitive (cf. Dretske 1972) and they are gradable. These two properties follow directly from the proposal developed here. In the vast literature on mood, the link between the appearance of the subjunctive mood and these important properties has never been made before.

The structure of this paper is as follows. In section 2, the relevant data are presented. In section 3, Heim $=\mathrm{s}(1992)$ semantics for desire predicates and emotive factive predicates is presented. In section 4, a new semantics for these predicates is developed based on the comparison of contextual alternatives. In section 5, the proposal is extended to all predicate classes that select the subjunctive mood in Spanish. In section 6, this proposal is compared to previous proposals for the semantics of these predicates (Giorgi and Pianesi1997, von Fintel1999). In section 7, I investigate the focus sensitivity of these predicates (cf. Dretske 1972,1975) and make a proposal for the semantic contribution of the subjunctive mood morpheme. Finally, in section 8, I present empirical evidence for the gradable nature of these predicates and refine my analysis: predicates that select the subjunctive mood are analyzed as having an extra degree argument.

\footnotetext{
Error! Main Document Only. See Portner (1999, 2003), as well as Villalta (2006) for an extensive discussion of traditional and recent approaches to the semantics of mood.
} 


\section{The distribution of subjunctive mood in Spanish complement clauses}

In Spanish, one important factor that determines whether the verb of an embedded clause is in the indicative or the subjunctive mood is the matrix predicate. The indicative mood is selected by epistemic predicates (e.g., saber $>$ know $=$, pensar $>$ think=, creer $>$ believe=), predicates of communication (e.g., decir $>$ say=, anunciar $>$ announce $=$ ), predicates of certainty (e.g., estar seguro $>$ be sure $=$, estar convencido $>$ be convinced $=$ ), commissives (e.g., prometer $>$ promise $=$ ), fiction verbs (e.g., soñar $>$ dream=), predicates of mental judgement (e.g. adivinar $>$ guess=, comprender $>$ understand $=$ ) and predicates of perception (e.g. notar $>$ notice $=$, ver $>$ see $=$, escuchar $>$ hear $=$ ). A few examples are presented in (1) through (4).

Victoria cree que hará

Victoria believes that PRO make:FUT.IND.3SG good weather.

$>$ Victoria believes that the weather will be good.=

(2) Sofía sabe que se ha planeado un picnic.

TO KNOW

Sofía knows that SE have:PAST.IND.3SG planned a picnic.

$>$ Sofía knows that a picnic has been planned .=

(3) Marcela dice que quiere venir. TO SAY

Marcela says that PRO want:PRES.IND.3SG come.

$>$ Marcela says that she wants to come.=

(4)

Sofía ha prometido que traerá el postre.

Sofía has promised that PRO bring:FUT.IND.3SG the dessert.

>Sofía has promised that she will bring the dessert.=

The subjunctive mood is selected by desire predicates (e.g., querer $>$ want $=$, preferir $>$ prefer $=$, temer $>$ fear $=$ ), emotive factive predicates (e.g., lamentarse $>$ regret $=$, alegrarse $>$ be glad $=$, sorprenderse $>$ be surprised $=$ ), modals (e.g., es possible $>$ it is possible $=$, es necesario $>$ es necesario=), predicates expressing doubt (e.g., dudar $>$ doubt=), directives (e.g., ordenar $>$ order $=$, 
aconsejar $>$ advise $=$, suggerir $>$ suggest $=$ ) and causatives (e.g., hacer $>$ make $=$, conseguir $>$ achieve $=$ ).

A few examples are presented below.

Victoria quiere que Marcela venga

al picnic.

TO WANT

Victoria wants that Marcela come:PRES.SUBJ.3SG to-the picnic.

$>$ Victoria wants Marcela to come to the picnic. $=$

(6) Sofía duda que Rafael pueda venir.

TO DOUBT

Sofia doubts that Rafael can:PRES.SUBJ.3SG come.

$>$ Sofía doubts that Rafael can come.=

(7)

Marcela se alegra de que

la hayan

invitado.

TO BE GLAD

Marcela SE glad of that PRO her have:PAST.SUBJ.3PL invited.

$>$ Marcela is glad that they have invited her.=

(8)

Victoria sugiere que salgan temprano.

TO SUGGEST

Victoria suggests that PRO leave:PRES.SUBJ.3PL early.

$>$ Victoria suggests that they leave early.=

It can be noted that, in both categories, we find factive as well as non-factive predicates. Sentences that contain factive predicates have the presupposition that the proposition expressed by the complement clause is true, contrary to sentences with non-factive predicates. Among the predicates that select the indicative mood, we find factive predicates such as saber ( $>$ know $=)$, acordarse $(>$ remember $=$ ) and olvidarse $(>$ forget $=$ ), as well as non-factives such as creer $(>$ believe $=)$, prometer $(>$ promise $=)$, decir $(>$ say $=)$ and $\operatorname{sonar}(>$ dream $=)$. Among the predicates that select the subjunctive mood, all emotive factive predicates and causative predicates are factive.

A number of predicates allow both the indicative and the subjunctive mood in their complement clause. Crucially, however, mood alternation then correlates with a meaning change in the predicate. Depending on the mood of the complement clause, the predicates fall under the corresponding predicate classes as described above. A few examples are presented below. 
The predicate sentir can either be interpreted as an emotive factive predicate ( $>$ be sorry $=$ ) and then selects the subjunctive mood, as in (9), or it can be interpreted as a predicate of perception ( $>$ sense $=/=$ have the impression $=$ ) and then selects the indicative mood, as in (10).

Siento que te hayan hecho daño.
PRO sorry that PRO you have:PAST.SUBJ.3PL done pain.
$>$ I am sorry that they have hurt you. $=$

Siento que va a haber un problema.

PRO sense that PRO go:FUT.IND.3SG to there-be a problem.

$>$ I have the impression that there is going to be a problem.=

The predicate decir can either be interpreted as a predicate of communication ( $>$ tell=/=say=) and then selects the indicative mood, as in (11), or it can be interpreted as a directive predicate (>order $=$ ) and then selects the subjunctive mood, as in (12). Most of the predicates of communication are ambiguous in this sense.

$$
\text { Te digo que acabaré a tiempo. }
$$

PRO you tell that PRO finish:FUT.IND.1SG on time.

$>$ I tell you that I will finish on time.=

$$
\text { Te dije que acabaras a tiempo. }
$$

PRO you told that PRO finish:PAST.SUBJ.2SG on time.

$>$ I told you to finish on time.=

Thus, when a predicate can select both the indicative and the subjunctive mood, the alternation correlates with a meaning change of the predicate. Notice, crucially, that the meaning change does not always correlate with a factive/non-factive distinction.

In the following, I turn to a first attempt at characterizing the semantics of the predicates that select the subjunctive mood in Spanish. 


\section{A semantics for the predicates that select the subjunctive mood in Spanish}

In this section, the goal is to develop a first proposal for a common semantics of the predicates that select the subjunctive mood in Spanish. I first present Heim=s (1992) proposal for desire predicates. Heim $=\mathrm{s}$ (1992) analysis of desire predicates builds on Stalnaker $=\mathrm{s}$ (1984) insight that every desire report contains a hidden conditional. AA little more explicitly, the leading intuition is that John wants you to leave means that John thinks that if you leave he will be in a more desirable world than if you don=t.@ (Heim 1992, p.193). I then argue that such a conditional semantics should be extended to all predicates that select the subjunctive mood in Spanish. ${ }^{2}$

\subsection{Heim=s (1992) conditional semantics for desire predicates}

We begin with the semantics for propositional attitude predicates first introduced by Hintikka (1969). The truth conditions for the verb believe are given in (13).

(13) $>\alpha$ believes $\varphi=$ is true in $w$ iff: $\quad w=0 \operatorname{Dox}_{\alpha}(w)$ : $\varphi$ is true in $w=$.

$\operatorname{Dox}_{\alpha}(\mathrm{w})$ contains all the worlds that are compatible with what $\alpha$ believes in the world w to be true, also called doxastic alternatives of $\alpha$ in $w$.)

The truth conditions in (13) say that $>\alpha$ believes $\varphi=$ is true in a world $w$ if and only if $\varphi$ is true in all worlds $\mathrm{w}=$ that are compatible with what $\alpha$ believes in $\mathrm{w}$. Thus, to take an example, John believes that it is raining is true in $\mathrm{w}$ iff it is raining in all the worlds $\mathrm{w}=$ that are compatible with what John believes in w.

Adopting the Hintikka-style analysis for a verb such as want results in the truth conditions given in (14). Here, the worlds compatible with $\alpha=\mathrm{s}$ beliefs in $\mathrm{w}$, the doxastic alternatives, have simply been replaced with the worlds compatible with $\alpha=$ s desires in $\mathrm{w}$, the so-called $>$ buletic $=$ alternatives.

Error! Main Document Only. Giannakidou (1998,1999), Portner $(1999,2003)$ and Quer $(1998,2001)$ also point out that the conditional semantics proposed by Heim (1992) is relevant for mood selection. But they do not discuss the consequences of adopting such a semantics. 
$>\alpha$ wants $\varphi=$ is true in $\mathrm{w}$ iff: $\mathrm{w}=0 \mathrm{Bul}_{\alpha}(\mathrm{w}): \varphi$ is true in $\mathrm{w}=$.

$\left(\mathrm{Bul}_{\alpha}(\mathrm{w})\right.$ contains all the worlds that are compatible with what $\alpha$ desires in $\mathrm{w}$, also called buletic alternatives of $\alpha$ in $w$.)

These truth conditions, however, cannot appropriately capture all the characteristics of the verb want. This becomes clear as soon as we look at an example more closely. The example in (15), from Heim (1992), illustrates that these truth conditions are problematic.

I want to teach Tuesdays and Thursdays next semester.

Heim notes that the sentence in (15) can be true in a situation in which in fact I would rather prefer not to teach at all. In a situation like this the following holds: in all the worlds that are compatible with what I desire I do not teach. If we adopt the truth conditions in (14), however, the sentence comes out as false in this situation: the proposition is only evaluated in worlds that are compatible with my desires, which do not include worlds in which I teach Tuesdays and Thursdays next semester.

To remedy this problem, Heim (1992) develops a new proposal for want that captures Stalnaker $=\mathrm{s}$ insight that every desire report employs a hidden conditional: $>$ to want something, is to prefer something to certain relevant alternatives, the relevant alternatives being those possibilities that the agent believes will be realizable if he doesn=t get what he wants. $=($ Stalnaker 1984, p.89). The sentence (15) can thus be paraphrased as in (16).

(16) If I teach Tuesdays and Thursdays next semester, I will be in a more desirable world than if I teach on other days next semester.

Heim $=\mathrm{s}$ new proposal for the truth conditions of want is based on the semantics adopted for conditionals. Following Lewis (1973) and Stalnaker (1968), a conditional if $\varphi, \psi$ is true in a world w iff $\psi$ is true in all $\varphi$-worlds maximally similar to w (where a $\varphi$-world is a world in which $\varphi$ is true). Thus, in (16), the sentence is true if and only if the consequent is true in all those worlds in which I teach Tuesday and Thursdays next semester and which are otherwise just like the actual world. By 
adopting such a conditional semantics, Heim proposes that the verb want has the truth-conditions in (17).

(17) $>\alpha$ wants $\varphi=$ is true in $w$ iff:

For every $\mathrm{w}=0 \operatorname{Dox}_{\alpha}(\mathrm{w})$ : Every $\varphi$-world maximally similar to $\mathrm{w}=$ is more desirable to $\alpha$ in $\mathrm{w}$ than any non- $\varphi$-world maximally similar to $w=$.

(Heim 1992, p.193)

We now apply this proposal to our previous example repeated here in (18).

I want to teach Tuesdays and Thursdays next semester.

Under the truth conditions presented above, for this sentence to be true, the following has to hold: for each doxastic alternative $\mathrm{w}=$, if I teach Tuesdays and Thursdays next semester in $\mathrm{w}=$, it is a more desirable world than maximally similar worlds in which I teach on other days. If I teach on other days in $\mathrm{w}=$, it is a less desirable world than maximally similar worlds in which I do teach on Tuesdays and Thursdays.

In Heim (1992), the truth conditions of this verb are stated in a context change semantics. Since I do not use this framework here, I present the equivalent truth conditions in a non-dynamic semantics $^{3}$. Heim encodes the relation of comparative similarity among worlds with a family of selection functions as in (19): for each world w, there is a selection function Sim $_{\mathrm{w}}$ from propositions to propositions which maps each proposition $\mathrm{p}$ to the set of worlds maximally similar to $w$ in which $\mathrm{p}$ is true (cf. Heim 1992, p.195).

(19) $\operatorname{Sim}_{\mathrm{w}}(\mathrm{p})=\{\mathrm{w}=0 \mathrm{~W}: \mathrm{w}=0 \mathrm{p}$ and $\mathrm{w}=$ resembles $\mathrm{w}$ no less than any other world in $\mathrm{p}\}$

\footnotetext{
${ }^{3}$ By using a dynamic framework, Heim solves a number of presupposition projection facts that will remain unaddressed here.
} 
Additionally, Heim uses an abbreviation for the ranking of possible worlds in terms of desirability. She introduces $>{ }_{\alpha, \mathrm{w}}{ }^{4}$, a relation between worlds, that can also be employed in an extended sense as a relation between sets of worlds, as defined in (20) (see Heim 1992, p.197).

(a) For any $\mathrm{w}, \mathrm{w}=, \mathrm{w}==0 \mathrm{~W}, \mathrm{w}=>_{\alpha, \mathrm{w}} \mathrm{w}==$ iff $\mathrm{w}=$ is more desirable to $\alpha$ in $\mathrm{w}$ than $\mathrm{w}==$

(b) For any $\mathrm{w} 0 \mathrm{~W}, \mathrm{X} \phi \mathrm{W}, \mathrm{Y} \phi \mathrm{W}, \mathrm{X}>_{\alpha, \mathrm{w}} \mathrm{Y}$ iff $\mathrm{w}=>_{\alpha, \mathrm{w}} \mathrm{w}==$ for all $\mathrm{w}=0 \mathrm{X}, \mathrm{w}==0 \mathrm{Y}$.

The truth conditions of the verb want can now be stated as in (21).

$$
\begin{aligned}
& \text { want }(\mathrm{p})(\mathrm{a})(\mathrm{w})=1 \text { iff } \\
& \mathrm{w}=0 \operatorname{Dox}_{\mathrm{a}}(\mathrm{w}): \operatorname{Sim}_{\mathrm{w}_{-}}(\mathrm{p})>_{\mathrm{a}, \mathrm{w}} \operatorname{Sim}_{\mathrm{w}_{-}}(5 \mathrm{p})
\end{aligned}
$$

Heim then suggests that this conditional semantics can be extended to other predicates such as wish and be glad. She argues, however, that there is an important difference between these predicates: in the case of the predicate want all the desirability comparisons should be entirely among worlds that the subject believes possible, contrary to predicates such as wish and be glad.

Heim thus proposes to further restrict the truth conditions of want. The truth conditions in (21) only require that all $\mathrm{p}$-worlds that are maximally similar to $\mathrm{w}=$ be more desirable than all $5 \mathrm{p}$-worlds maximally similar to $\mathrm{w}=$. Nothing is said about whether these maximally similar worlds have to be doxastic alternatives or not. In the new proposal, in (22), all desirability comparisons are entirely among the subject $=\mathrm{s}$ belief worlds, because the argument of the similarity function Sim applies to a subset of the doxastic alternatives. The function Sim now returns the set of worlds that are an element of $\operatorname{Dox}_{a}(w) 1 p$ and $\operatorname{Dox}_{a}(w) 15 p$ respectively and which resemble w no less than any other world.

\section{Conditional semantics for want}

want $(\mathrm{p})(\mathrm{a})(\mathrm{w})=1$ iff

$$
\mathrm{w}=0 \operatorname{Dox}_{\mathrm{a}}(\mathrm{w}): \operatorname{Sim}_{\mathrm{w}}\left(\operatorname{Dox}_{\mathrm{a}}(\mathrm{w}) 1 \mathrm{p}\right)>_{\mathrm{a}, \mathrm{w}} \operatorname{Sim}_{\mathrm{w}=}\left(\operatorname{Dox}_{\mathrm{a}}(\mathrm{w}) 15 \mathrm{p}\right)
$$

\footnotetext{
Error! Main Document Only. To express that $\mathrm{X}$ is more desirable than $\mathrm{Y}$, I will use $\mathrm{X}>_{\alpha, \mathrm{w}} \mathrm{Y}$ rather than $\mathrm{X}<_{\alpha, \mathrm{w}} \mathrm{Y}$ as is originally done in Heim (1992). The definition is otherwise identical to the one in Heim(1992).
} 
It is exactly in this aspect that the predicate want differs from a predicate such as wish. This is best illustrated with an example.

John wishes he taught on Tuesdays and Thursdays.

This sentence can only be judged to be true in a situation in which John believes that he doesn $=t$ teach on Tuesdays and Thursdays. Hence, the worlds compatible with his beliefs only include worlds in which he doesn=t teach on Tuesdays and Thursdays. Thus, we cannot adopt the same truth conditions as for want. If all desirability comparisons are entirely among the subject=s belief worlds, the set on the left hand side of the comparison relation will always be empty. Heim proposes that, for the verb wish, the proposition $\mathrm{p}$ is evaluated with respect to a revision of the worlds compatible with

his beliefs, a set that will also include some p-worlds. Heim proposes that this revised set of worlds results from $\operatorname{Dox}_{\mathrm{a}}(\mathrm{w})$ by suspending some of the assumptions in $\operatorname{Dox}_{\mathrm{a}}(\mathrm{w})$, as in the revision of a context necessary for the interpretation of counterfactuals. The definition proposed in Heim (1992) is stated in a context change semantics and is not suitable for the semantics adopted here. I will assume here that the revision of the doxastic alternatives with respect to a proposition $\mathrm{p}$, which I call $\operatorname{rev}_{\mathrm{p}}\left(\operatorname{Dox}_{\mathrm{a}}(\mathrm{w})\right)$, contains all the worlds in $\operatorname{Dox}_{\mathrm{a}}(\mathrm{w})$ as well as all the p-worlds most similar to w.

We can now adopt the truth conditions of the predicate wish given in (24). Here, in the first argument of the ordering relation $>_{\mathrm{a}, \mathrm{w}}$, the function Sim applies to worlds that are included in the revision of the doxastic alternatives.

\section{Conditional semantics for wish}

$$
\begin{aligned}
& \text { wish }(\mathrm{p})(\mathrm{a})(\mathrm{w})=1 \text { iff } \\
& \mathrm{w}=0 \operatorname{Dox}_{\mathrm{a}}(\mathrm{w}): \operatorname{Sim}_{\mathrm{w}}\left(\operatorname{rev}_{\mathrm{p}}\left(\operatorname{Dox}_{\mathrm{a}}(\mathrm{w})\right) 1 \mathrm{p}\right)>_{\mathrm{a}, \mathrm{w}} \operatorname{Sim}_{\mathrm{w}_{=}}\left(\operatorname{Dox}_{\mathrm{a}}(\mathrm{w}) 15 \mathrm{p}\right)
\end{aligned}
$$

Heim (1992) furthermore extends her proposal to the predicate be glad.

(25) John is glad that he teaches on Tuesdays and Thursdays.

The sentence in (25) has the presupposition that John believes in the truth of the complement, i.e. John believes that he teaches on Tuesdays and Thursdays. In this case, John=s doxastic 
alternatives do not include worlds in which he doesn=t teach on Tuesdays and Thursdays. Hence, for the predicate be glad, it is in the second argument of the ordering relation $>_{\mathrm{a}, \mathrm{w}}$, that the function $\operatorname{Sim}$ applies to worlds that are included in a revision of the doxastic alternatives. The truth conditions of the predicate be glad are given in (26).

\section{Conditional semantics for be glad}

$$
\begin{aligned}
& \text { be } \operatorname{glad}(\mathrm{p})(\mathrm{a})(\mathrm{w})=1 \\
& \mathrm{w}=0 \operatorname{Dox}_{\mathrm{a}}(\mathrm{w}): \operatorname{Sim}_{\mathrm{w}}\left(\operatorname{Dox}_{\mathrm{a}}(\mathrm{w}) 1 \mathrm{p}\right)>_{\mathrm{a}, \mathrm{w}} \operatorname{Sim}_{\mathrm{w}}\left(\operatorname{rev}_{5 \mathrm{p}}\left(\operatorname{Dox}_{\mathrm{a}}(\mathrm{w})\right) 15 \mathrm{p}\right)
\end{aligned}
$$

To summarize, in Heim (1992), predicates such as wish, want and be glad share their core semantics, a conditional semantics. They have the common feature that for each doxastic alternative, two sets of worlds are compared. The only difference between these predicates lies in whether the relevant sets of worlds are included in the doxastic alternatives of the subject or rather in a revision of the doxastic alternatives of the subject.

\subsection{A conditional semantics for predicates that select the subjunctive mood}

After this brief presentation of Heim=s semantics for desire predicates, we now return to the class of predicates that select the subjunctive mood in Spanish. The predicates discussed by Heim (1992) all select the subjunctive mood in Spanish. My hypothesis will be that the conditional semantics adopted so far can also be extended to all other predicate classes that select the subjunctive mood in Spanish, such as modals, predicates of doubt, directives and causatives. This hypothesis naturally accommodates the fact that among the predicates that select the subjunctive mood we find factive as well as non-factive predicates. The semantic property shared by these predicates is that they establish a comparison. Whether this comparison is between worlds that are among the doxastic alternatives of the subject or not is irrelevant for mood selection.

Under this hypothesis, the predicates that select the subjunctive mood in Spanish share the following common property: they introduce an ordering relation or scale. It is important to observe that the ordering relation expressed by the predicate is not a relation of desirability for all predicates. For instance, predicates such as sorprenderse $>$ be surprised $=$ and $d u d a r>\mathrm{doubt}=$ rather require an ordering relation of likelihood. Also, a number of emotive factive predicates cannot be based on the 
notion of desirability, such as es interesante (>it is interesting=), es divertido ( $>$ it is amusing=), etc. I will assume that the ordering relation is contributed by the lexical meaning of each predicate. This is reminiscent of what has been said about the meaning of gradable adjectives in the literature. The scalar approaches to the semantics of gradable adjectives argue that the meaning of a gradable adjective such as tall directly contributes the dimension of the scale involved (in the case of tall the dimension is height). ${ }^{5}$

Below, I present a first attempt at a characterization of the predicates that select the subjunctive mood in Spanish, as stated in (27).

\section{Preliminary hypothesis for the subjunctive mood in Spanish}

A proposition $\mathrm{p}$ that is the complement of the matrix predicate requires the subjunctive mood iff the matrix predicate introduces an ordering relation and compares $\mathrm{p}$ to non-p.

To conclude, I have proposed to adopt Heim=s (1992) conditional semantics to characterize the predicates that select the subjunctive mood in Spanish. In the following, I present two arguments that call for a revision of this semantics.

\section{A new proposal: comparison of contextual alternatives}

In this section, I propose to revise the semantics for the predicates that select the subjunctive mood in Spanish. First, I argue that their semantics involves comparison of the embedded proposition $\mathrm{p}$ with contextually available alternatives, rather than simply with $5 \mathrm{p}$. Second, I argue that, in the truth conditions, reference to the subject=s beliefs can be replaced with the set of contextually available alternatives. I then develop a new analysis for these predicates.

\footnotetext{
Error! Main Document Only. For approaches that adopt a scalar semantics for gradable adjectives see Bartsch and Venneman 1973, Bierwisch 1989, Cresswell 1976, Kamp 1975, Kennedy 1999, Klein E. 1980, 1991, Rullmann 1995, Schwarzschild \& Wilkinson 1999, Seuren 1973, von Stechow 1984a,1984b, and many others.
} 


\subsection{When more than two contextual alternatives are available}

The central point to be made in this section is that the semantics of the predicates selecting the subjunctive mood requires comparison of contextual alternative propositions. In fact, the semantics adopted so far is based on a special case where the context only provides the alternatives $\mathrm{p}$ and $5 \mathrm{p}$. Contexts providing more than two alternatives illustrate this issue quite clearly. Consider the scenario in (28).

(28) Sofía has promised to bring a dessert to the picnic. Victoria believes that there are three possibilities for what she may actually do. She could prepare a chocolate cake, even though Victoria considers that extremely unlikely because it represents far too much work. She might bring an apple pie, which Victoria considers very likely since she can just buy it at the bakery nearby. Or Sofía might bring ice-cream, which seems most likely to Victoria, since she usually has some in her freezer. Victoria prefers the chocolate cake over the apple pie and the apple pie over the ice-cream.

The schematic figure in (29) represents the two scales involved in this scenario, desirability according to Victoria and likelihood according to Victoria. That Sofía will bring the chocolate cake is the most desirable and most unlikely alternative; that she will bring the ice cream is the least desirable and most likely alternative.

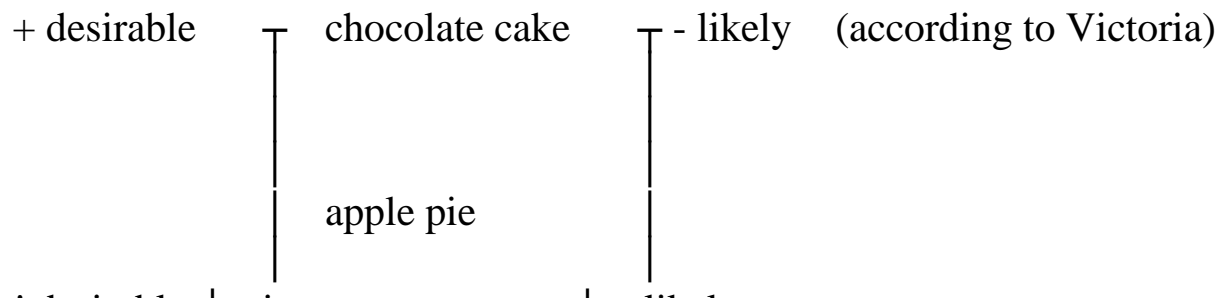

$$
\begin{aligned}
& \text { ! desirable } \perp \text { ice cream } \perp+\text { likely }
\end{aligned}
$$

In this situation, the sentence in (30) is intuitively judged to be false.

(30) Victoria wishes Sofía would bring an apple pie. 
Contrary to intuitions, Heim=s conditional semantics for the verb wish predicts that this sentence should come out as true in this scenario. Under Heim $=$ s proposal, the sentence (30) is true iff for all worlds $\mathrm{w}=$ that are compatible with Victoria=s beliefs, the worlds in which Sofía brings the apple pie are more desirable to Victoria than all the minimally different worlds in which she doesn=t. This is true, since, in the given scenario, the closest worlds in which Sofía doesn=t bring an apple pie are worlds in which she brings ice-cream. This set does not contain worlds in which she brings chocolate cake (these are not minimally different for Victoria since she considers them as extremely unlikely). A conditional semantics thus does not make the correct predictions for this scenario.

Other predicates give rise to similar effects in contexts that make more than two alternatives available. Imagine that, in the continuation of the previous scenario, Sofía does in fact bring the apple pie to the picnic. The sentence in (31) can then be true in that situation.

(31) Victoria is disappointed that Sofía brought an apple pie.

A conditional semantics for the predicate be disappointed, however, predicts (31) to be false in this scenario. Simplifying somewhat, I will assume that the only difference between the semantics of be disappointed and be glad is that the ordering relation of desirability is reversed. The truth conditions of be disappointed then predict that the worlds in which Sofía brought the apple pie are less desirable to Victoria than all the minimally different worlds in which she doesn=t. This is false, since the closest worlds are all worlds in which she brings ice-cream. She considers these worlds as less desirable. Again, a conditional semantics does not make the correct predictions for a scenario as described above.

I conclude that the semantics of the predicates under discussion involves comparison of $\mathrm{p}$ with the set of its contextual alternatives rather than with just $5 \mathrm{p}$. I propose to adopt a new lexical entry for want as in (32). The difference with the previous lexical entry for want is that, here $5 \mathrm{p}$ is replaced by the contextually given alternatives $q$.

\section{(32) Semantics of want based on comparison of alternatives}

want $_{\mathrm{C}}{ }^{\mathrm{g}}(\mathrm{p})(\mathrm{a})(\mathrm{w})=1$ iff

q: q p \& q 0 g(C): $\operatorname{Sim}_{w_{-}}\left(\operatorname{Dox}_{a}(w) 1\right.$ p) $>_{a, w} \operatorname{Sim}_{w_{-}}\left(\operatorname{Dox}_{a}(w) 1\right.$ q) 
In the lexical entry in (32), the verb want carries an index $\mathrm{C}$ that stands for a variable anaphoric to a contextually determined set of propositions (it is an index of type $\langle\langle s, t\rangle, t\rangle>$ ). This variable receives its content from the variable assignment g. Variables of this kind have also been used before for similar purposes, such as for the domain of quantification of only in Rooth (1985, 1992) and the resource domain of adverbs of quantification in von Fintel (1994), as well as the contextual restriction of determiners in Westerståhl (1985), and others.

To conclude, in this section, I have argued that comparison between $\mathrm{p}$ and $5 \mathrm{p}$ is a special case of comparison of $\mathrm{p}$ with its contextual alternatives. I now turn to one further revision of the semantics of these predicates.

\subsection{Reference to the doxastic alternatives}

In what follows, I argue that, in Heim=s semantics for desire predicates, the desires of the subject are too tightly connected to his/her beliefs. In fact, Heim=s semantics predicts that for sentences containing desire predicates certain inferences should be possible, contrary to our intuitions. Imagine a situation in which my choices for my teaching schedule of the next semester depend on how much work I get done this semester. The conclusion in (33c), nevertheless cannot be inferred.

(33) a) I want to teach Tuesdays and Thursdays next semester.

b) I believe that I will teach Tuesdays and Thursdays next semester if and only if I work hard now.

c) Invalid inference:

I want to work hard now.

The conditional semantics for the predicate want, however, predicts that this inference should be valid. For clarification, I repeat Heim $=$ s conditional semantics for the predicate want.

\section{Conditional semantics for want}

want $(\mathrm{p})(\mathrm{a})(\mathrm{w})=1$ iff

$\mathrm{w}=0 \operatorname{Dox}_{\mathrm{a}}(\mathrm{w}): \operatorname{Sim}_{\mathrm{w}}\left(\operatorname{Dox}_{\mathrm{a}}(\mathrm{w}) 1 \mathrm{p}\right)>_{\mathrm{a}, \mathrm{w}} \operatorname{Sim}_{\mathrm{w}}\left(\operatorname{Dox}_{\mathrm{a}}(\mathrm{w}) 15 \mathrm{p}\right)$ 
According to (34), from the truth of (33a) it follows that in $\operatorname{Dox}_{I}(w)$ all the worlds in which I teach Tuesdays and Thursdays next semester are more desirable than maximally similar worlds in which I don=t teach on Tuesdays and Thursdays next semester. From the truth of (33b) it follows that in $\operatorname{Dox}_{I}(w)$ the worlds in which I teach Tuesdays and Thursdays next semester correspond exactly to those worlds in which I work hard this semester. Hence, from (33a) and (33b) it follows that in $\operatorname{Dox}_{\mathrm{I}}(\mathrm{w})$ all worlds in which I work hard this semester are more desirable than maximally similar worlds in which I don=t work hard this semester. As a result, the inference is expected to be valid, and (33c) is expected to be true, contrary to what we observe.

The invalid inference illustrates that someone may believe that two propositions $\mathrm{p}$ and $\mathrm{q}$ are true in the exact same set of worlds, and at the same time want $\mathrm{p}$ without wanting $\mathrm{q}$. Heim=s semantics cannot capture this fact. As a consequence, I propose to eliminate the reference to the doxastic alternatives and simply replace it with the set of contextually relevant alternatives.

The proposal made in (32) can then be simplified accordingly, as in (35) along with a slight modification of the definition of $>_{\alpha, w}{ }^{6}$ :

\section{Semantics of want based on comparison of alternatives}

$$
\begin{aligned}
& \text { want }_{\mathrm{C}}{ }^{\mathrm{g}}(\mathrm{p})(\mathrm{a})(\mathrm{w})=1 \text { iff } \\
& \mathrm{q}: \mathrm{q} \quad \mathrm{p} \& \mathrm{q} 0 \mathrm{~g}(\mathrm{C}): \mathrm{p}>_{\text {DES } \alpha, w} \mathrm{q}
\end{aligned}
$$

where $>_{\mathrm{DES} \alpha, \mathrm{w}}$ is defined as follows

a) For any $\mathrm{w}, \mathrm{w}=, \mathrm{w}==0 \mathrm{~W}, \mathrm{w}=>_{\alpha, \mathrm{w}} \mathrm{w}==$ iff $\mathrm{w}=$ is more desirable to $\alpha$ in $\mathrm{w}$ than $\mathrm{w}==$.

b) For any $p \phi W, q \phi W, p>_{D E S} \alpha, w$ iff $\quad w==0 q \quad w=0 p$ such that $w=>_{\alpha, w} w==$, and it is not the case that $\quad \mathrm{w}=0 \mathrm{p} \quad \mathrm{w}==0 \mathrm{q}$ such that $\mathrm{w}==>_{\alpha, \mathrm{w}} \mathrm{W}=$.

Error! Main Document Only. In (35), I propose to use a new definition of $>_{\mathrm{DES} \alpha, \mathrm{w}}$, adapted from the definition of $>$ better possibility= in Kratzer(1991), since the ordering relation defined in Heim (1992) is not suitable for comparative desirability among propositions. This is so, since Heim=s definition makes a requirement that is too strong. If we were to apply it to propositions we would run into the following problem: if $\mathrm{p}$ is more desirable than $\mathrm{q}$, the definition requires that all worlds in $\mathrm{p}$ be more desirable than all worlds in $\mathrm{q}$. However, some worlds in $\mathrm{p}$ may be really bad worlds for other reasons, and may still not necessarily affect the desirability relation between $\mathrm{p}$ and q. Kratzer=s definition of $>$ better possibility $=$ solves this problem. 
With the semantics proposed in (35), no inference is expected. The new semantics predicts that $>$ I teach Tuesdays and Thursdays $=$ is more desirable than its contextually relevant alternatives (for example $>$ I teach Mondays, Wednesdays and Fridays=). However, from the fact that $>$ I teach Tuesdays and Thursdays next semester $=$ and $>$ I work hard this semester $=$ are true in the exact same set of worlds it does not follow that $>$ I want to work hard this semester $=$. This is so, since in both cases we are comparing a different set of alternatives. For example, the set of alternatives for $>$ I work had this semester $=$ may be $\{>\mathrm{I}$ don $=\mathrm{t}$ work this semester $=,>\mathrm{I}$ work a little this semester $=\}$. As a consequence, no inference is expected.

With the semantics proposed here, however, two new problems arise. First, we cannot account anymore for the fact that the subject=s beliefs do sometimes play a role in determining the truth conditions of a want-sentence. Take the example in (36).

John doesn=t have to teach at all next semester but he thinks he does and he wants to teach Tuesdays and Thursdays.

In this sentence, the alternative AJohn doesn=t teach at all next semester@ is provided in the context, however, it cannot be part of the set of alternatives that is relevant for the comparison. If this were so, we would not predict the correct truth conditions. Hence, the subject=s beliefs do play a role in determining which alternatives enter the comparison.

A second problem is that we cannot express the difference between want, wish and be glad anymore. As we saw before, these predicates precisely differ in terms of whether the subject believes that the proposition expressed by the complement clause is true or not. As a consequence, I propose to distinguish these predicates in terms of their definedness conditions.

Below, I adopt a semantics in which the predicate want has a definedness condition which requires that all contextual alternatives be included in the doxastic alternatives ${ }^{7}$.

\section{Semantics of want based on comparison of alternatives}

$$
\text { want }_{\mathrm{C}}{ }^{\mathrm{g}}(\mathrm{p})(\mathrm{a})(\mathrm{w}) \text { is defined iff } \mathrm{q} 0 \mathrm{~g}(\mathrm{C}) \text { : } \operatorname{Dox}_{\mathrm{a}}(\mathrm{w}) 1 \mathrm{q} \quad \mathrm{l}
$$

\footnotetext{
${ }^{7}$ Further refinements may be necessary. As an anonymous reviewer points out, the predicate want requires that $p$ be a desirable alternative, unlike the predicate prefer. That is, in a context in which Victoria considers all alternatives as highly undesirable it is still possible to say that Victoria prefers $p$, but not that Victoria wants $p$.
} 
if defined want $_{\mathrm{C}}{ }^{\mathrm{g}}(\mathrm{p})(\mathrm{a})(\mathrm{w})=1$ iff

$\mathrm{q}: \mathrm{q} \quad \mathrm{p} \& \mathrm{q} 0 \mathrm{~g}(\mathrm{C}): \mathrm{p}>_{\mathrm{DES} \alpha, \mathrm{w}} \mathrm{q}$

I will show that this new proposal still does not predict the practical inference discussed earlier to be valid. The practical inference is repeated here.

(38) a) I want to teach Tuesdays and Thursdays next semester.

b) I believe that I will teach Tuesdays and Thursdays next semester if and only if I work hard now.

c) Invalid inference:

I want to work hard now.

According to (37), from the truth of (38a) it follows that $>$ I teach Tuesdays and Thursdays next semester $=$ is more desirable to me than its contextual alternatives, for example $>$ I teach Mondays, Wednesdays and Fridays next semester $=$. From the truth of $(38 b)$ it follows that in $\operatorname{Dox}_{\mathrm{I}}(\mathrm{w})$ the worlds in which I teach Tuesdays and Thursdays next semester correspond exactly to those worlds in which I work hard this semester. From this, however, it does not follow that (38c) is true. (38c) says that $>$ I work hard now $=$ is more desirable than its contextual alternatives, for instance $\{>\operatorname{Idon}=\mathrm{t}$ work at all $=,>$ I work a little $=\}$. Even if the propositions $>$ I teach Tuesdays and Thursdays next semester $=$ and $>$ I work hard now $=$ are true in the same set of worlds, their contextual alternatives are not necessarily the same.

I propose that the predicates wish and be glad will then have slightly different definedness conditions. The fact that the predicate wish requires that the proposition $\mathrm{p}$ should not be included in the subject $=\mathrm{s}$ doxastic alternatives, whereas the predicate be glad requires that the proposition $\mathrm{p}$ necessarily be true in the subject $=\mathrm{s}$ doxastic alternatives can now be expressed in their definedness conditions.

(39) Semantics of wish based on comparison of alternatives

wish $_{\mathrm{C}}{ }^{\mathrm{g}}(\mathrm{p})(\mathrm{a})(\mathrm{w})$ is defined iff $\mathrm{p} 1 \operatorname{Dox}_{\mathrm{a}}(\mathrm{w})=\mathrm{l}$

If defined wish $_{\mathrm{C}}{ }^{\mathrm{g}}(\mathrm{p})(\mathrm{a})(\mathrm{w})=1$ iff

$\mathrm{q}: \mathrm{q}$ p \& q $0 \mathrm{~g}(\mathrm{C}): \mathrm{p}>_{\mathrm{DES} \alpha, \mathrm{w}} \mathrm{q}$ 


\section{Semantics of be glad based on comparison of alternatives}

be $\operatorname{glad}_{\mathrm{C}}{ }^{\mathrm{g}}(\mathrm{p})(\mathrm{a})(\mathrm{w})$ is defined iff $\operatorname{Dox}_{\mathrm{a}}(\mathrm{w}) \phi \mathrm{p}$

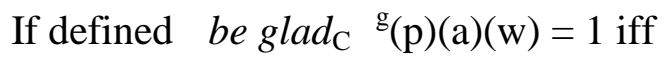

$\mathrm{q}: \mathrm{q} \quad \mathrm{p} \& \mathrm{q} 0 \mathrm{~g}(\mathrm{C}): \mathrm{p}>_{\mathrm{DES} \alpha, \mathrm{w}} \mathrm{q}$

The lexical entries provided here are certainly a simplification, given that the precise definedness conditions of these predicates are a rather complex matter (cf. von Fintel 1992). Since my main aim is to show that these different predicates share a core semantics, I will not go into further discussion of the details of these definedness conditions here, but adopt a simplified semantics that is sufficient for the argumentation developed here.

I will now propose that the semantics based on comparison of contextual alternatives can be extended to all predicates that select the subjunctive mood in Spanish:

\section{(41) New hypothesis for the subjunctive mood in Spanish}

A proposition $\mathrm{p}$ that is the complement of the matrix predicate requires the subjunctive mood iff the matrix predicate introduces an ordering relation between propositions and compares $p$ to its contextually available alternatives.

To conclude, in this section, I have developed a new hypothesis for the semantics of the predicates that select the subjunctive mood in Spanish. By revising Heim=s (1992) proposal, I have developed a semantics of comparison for predicates such as want, be glad and wish. The new semantics involves comparison of contextual alternatives to the proposition expressed by the complement clause. In the next section, I discuss how the presented analysis can be extended to all predicate classes that select the subjunctive mood.

\section{The predicate classes that select the subjunctive mood in Spanish}

In this section, I will go over all predicate classes that select the subjunctive mood in Spanish to show how their semantics can be captured by the generalization. While it is impossible to present a 
full fledged analysis for every single predicate class here, I will briefly sketch possible ways of analyzing the different classes under the presented proposal. The exact semantics of causative predicates will however be left for future research.

\subsection{Desire predicates and Emotive Factive Predicates}

In the previous section, I have discussed the desire predicates want and wish and emotive factive predicates such as be glad and be disappointed. The analysis can in principle be extended to all other predicates in these two classes, but there are two important factors that may vary.

The first factor of variation is the dimension of the scale which may differ from predicate to predicate. This scale should be contributed directly by the lexical meaning of the predicate. Desire predicates such as querer $(>$ want $=$ ) and esperar $(>$ hope $=$ ) contribute an ordering relation of desirability. For the class of emotive factive predicates there is more variation in terms of what dimension is contributed. Many emotive factive predicates contribute a relation of desirability, such as alegrarse ( $>$ be glad $=$ ) and estar contento ( $>$ be happy=), or a reverse relation of desirability, such as lamentarse (>regret=), or enfadarse (>be upset=). However, a number of other emotive factive predicates cannot be based on the notion of desirability such as es interesante ( $>$ it is interesting=), es divertido (>it is amusing=), es útil (>it is useful=), es fascinante (>it is fascinating=), etc. I will assume that the ordering relation is contributed by the lexical meaning of each predicate. Parallel to the scalar approaches to the semantics of gradable adjectives, I will propose that gradable predicates directly contribute the dimension of the scale involved.

The second factor of variation is the ranking of $\mathrm{p}$ among the alternatives. The proposal developed here leaves room for expressing that $\mathrm{p}$ may be the best, the worst or just a good alternative. While I have argued here that these predicates require $\mathrm{p}$ to be the best (or highest ranked) among the contextual alternatives, we will see in section 6.2.3 that not all predicates require that $\mathrm{p}$ be the best alternative, but rather that $\mathrm{p}$ be a good alternative (such as, for example, alegrarse $>$ be glad $=$ or lamentarse $>$ be disappointed $=$ ).

\subsection{Modals and predicates expressing likelihood and doubt}


Modal predicates, which select the subjunctive mood in Spanish, can be captured by the generalization quite straightforwardly. I will illustrate this here with the predicate es necesario $>$ be necessary $=$. Krasikova (2007) argues that have to-like modals such as have to, need, be required, be necessary etc. are associated with the likelihood scale/scale of comparative possibility when they express teleological modality. ${ }^{8}$ Parallel to Krasikova=s (2007) analysis, I will define the lexical entry for the predicate be necessary as follows:

\section{Semantics of be necessary based on comparison of alternatives}

$$
\text { be necessary }_{\mathrm{C}}{ }^{\mathrm{g}}(\mathrm{p})(\mathrm{w})=1 \text { iff } \mathrm{q}: \mathrm{q} \text { p \& } \mathrm{q} 0 \mathrm{~g}(\mathrm{C}): \mathrm{p}>_{\text {LIKELYw }} \mathrm{q}
$$

where $>_{\text {LIKELYw }}$ is defined as follows:

a) For any $w, w=, w==0 \mathrm{~W}, \mathrm{w}=>_{\mathrm{w}} \mathrm{w}==$ iff $\mathrm{w}=$ is closer to $\mathrm{w}$ than $\mathrm{w}==$.

b) For any $p \phi W, q \phi W, p>_{\text {LIKELYw }} q$ iff $\quad w==0 q \quad w=0 p$ such that $w=>_{\alpha w} w==$, and it is not the case that $\mathrm{w}=0 \mathrm{p} \quad \mathrm{w}==0 \mathrm{q}$ such that $\mathrm{W}==>_{, \mathrm{w}} \mathrm{W}=$.

The likelihood scale as defined here is based on comparative similarity (closeness to the actual world, cf. Lewis1986). Other predicates from this class such as es probable (>it is likely=), es posible ( $>$ it is possible $=)$ and $d u d a r(>d o u b t=)$ can also be analyzed as contributing the scale of likelihood. There may again be variation concerning the ranking of $\mathrm{p}$ among the contextual alternatives. For example, in the case of es posible ( $>$ it is possible $=$ ), the requirement will be that $\mathrm{p}$ is not the best alternative.

Here as well, there will be variation in the kind of scale contributed by the predicate: when modals express other kinds of modalities (such as deontic or bouletic modalities), the scale contributed is a different one (such as ranking based on the closeness to the ideal or law, cf. Lewis 1986).

\footnotetext{
${ }^{8}$ She argues this on the basis of the fact that their ability to induce the more than minimum reading in comparatives correlates to their ability to appear in sufficiency modal constructions (cf. Von Fintel \& Iatridou 2007).
} 
Sloman (1970) in fact already proposes an analysis equivalent to the one presented here for sentences containing the predicate $o u g h t .^{9}$ In order to capture their various possible interpretations (modal can, must and directive interpretation), he develops an analysis in which alternatives are compared with respect to a contextually determined ordering relation. He proposes that the interpretation of It ought to be the case that $p$ should be $>\mathrm{p}$ is, or is a necessary condition for the best, relative to the basis B, of the possibilities in the class Z.= (Sloman 1970, p. 389). B here stands for basis of comparison (dimension of the ordering relation), which is contextually given when not specified explicitly. $Z$ stands for the comparison class. Sloman claims that possible different meanings of ought fall out of differences in basis of comparison as well as differences in comparison class.

\subsection{Directive predicates}

Portner $(2004,2007)$ proposes that imperative sentences are used to contribute to the discourse component that he labels the To-do List, more precisely the addressee $=\mathrm{s}$ To-do List. A To-do List is a set of propositions that the participant intends to make true. In short, imperative sentences are used to make requirements, where the essential function of a requirement is to add a proposition to someone $=\mathrm{s}$ To-Do List. Just as declarative sentences are used to make assertions and contribute to the common ground, in Portner $(2004,2007)$, imperatives are used to make requirements and contribute to the addressee $=\mathrm{s}$ To-Do List. Another important feature of his analysis is that the To-Do List is considered to be a subset of the ordering source (cf. Kratzer 1981) and thus contributes to imposing an ordering on the common ground.

Turning now to directive predicates such as mandar ( $>$ order $=$ ), ordenar $(>$ order $=)$, pedir ( $>$ ask $=$ ), we can show that, by adopting Portner=s main ideas, these can be accommodated in the proposal developed here. I propose that they make reference to the To-Do List and that the relevant set of propositions are those propositions that are part of (or a subset of) the set of contextual alternatives. The ordering relation is introduced by the predicate. For deontic predicates, such as to order, I propose the following semantic definition:

\section{(43) Semantics of to order based on comparison of alternatives}

9 I thank Kai von Fintel for pointing this out to me. 
$\operatorname{order}_{\mathrm{C}}^{\mathrm{g}}(\mathrm{p})(\mathrm{x})(\mathrm{w})=1$ iff $\mathrm{x}$ requires that

$$
\mathrm{q}: \mathrm{q} \text { p \& q } 0 \mathrm{~g}(\mathrm{C}) \& \mathrm{q} 0 \mathrm{~T}(\alpha): \mathrm{p}>_{\text {DEONTICw }} \mathrm{q}
$$

where $\mathrm{T}(\alpha)$ is the set of propositions (>To-Do List=) assigned to a participant $\alpha$ in the conversation

The ordering relation contributed by the predicate may vary. In Portner(2007), the ordering imposed may vary depending on what is expressed by the imperative: when the imperative expresses an order, it will be a deontic ordering source, when it expresses an invitation, it will express a bouletic ordering source, when it expresses a suggestion, it will express a teleological ordering source.

Notice that under this proposal the semantics of directives is slightly different from the other predicate classes that select the subjunctive mood: the comparative meaning component is embedded more deeply within the meaning of the predicate.

\subsection{Causative predicates}

In the case of causatives such as hacer $(>$ make $=)$ and lograr $(>$ achieve $=)$, I propose that the relevant comparison relation is one of comparative similarity. Causatives are usually analyzed with the semantics of counterfactual conditionals. In Lewis (1973), it is proposed that, in a counterfactual, all worlds in which the antecedent is true are ordered with respect to their similarity to the actual world. For a causative predicate this means that, all worlds in which the embedded proposition is true will be compared to the actual world with respect to their similarity. This ordering relation may also be defined for propositions (cf Lewis 1986) as was done for modal predicates in section 5.2. Hence, the predicate cause can be defined as expressing that $\mathrm{p}$ is the closest to the actual world among the set of contextual alternatives.

I suggest that predicates such as hacer $(>$ make $=)$ and lograr $(>$ achieve $=)$ contain the predicate cause as part of their meaning. Hence, similarly to directive predicates, the relevant comparison will be embedded more deeply within the meaning of the predicate. Even though I will not go into the details of a semantics of causatives here, we can assume that they share with the other predicates classes the fact that they contribute an ordering relation and compare $\mathrm{p}$ its contextual alternatives. 


\section{Comparing the proposal to other approaches}

In this section, I compare my proposal to other existing proposals on the semantics of propositional attitude predicates.

Propositional attitude predicates have received a lot of interest in the semantic and philosophical literature independently of the issues of mood selection. Since Hintikka $(1962,1969)$, predicates such as believe, know and want have commonly been analyzed with a semantics of possible worlds, more specifically with a semantics of modal necessity: $\alpha$ believes/knows/wants $\varphi$ is true in $\mathrm{w}$ iff $\varphi$ is true in all the worlds that are compatible with $\alpha=\mathrm{s}$ beliefs/knowledge/desires in $\mathrm{w}$. The question then is to what extent a Hintikka-style semantics could be extended to all kinds of propositional attitudes. In a similar vein, recent approaches have proposed that propositional attitudes should be modeled after the semantics of modal expressions involving a semantics of necessity and possibility (cf., for example Kiefer 1987, von Fintel 1999, Giorgi and Piannesi 1997).

In this section, I explicitly compare my proposal to these approaches. As we have already seen before, a Hintikka-style semantics has its problems when extended to desire predicates. I will show here that there are a number of characteristics of the predicates that select the subjunctive mood that are difficult to account for in this type of approach. We will see that, on the contrary, these characteristics follow straightforwardly from the proposal that I have adopted here.

I now turn to making explicit how the meaning common to the predicates that select the subjunctive mood can be expressed with a semantics of modal necessity or modal possibility, following von Fintel(1999). Since he makes use of the semantics proposed in Kratzer (1997, 1981, 1999) to capture the meaning properties of predicates such as want, wish, be glad and be sorry, I first present a brief overview of Kratzer=s theory of modality.

\subsection{A semantics of modal necessity/possibility}

Kratzer $(1977,1981,1991)$ develops a semantics in which modal expressions receive meanings that are dependent on two contextual parameters, a modal base and an ordering source. These two parameters are determined by two conversational backgrounds. 
Kratzer points out that there are many different kinds of conversational backgrounds. A conversational background is the kind of entity denoted by expressions such as what the law provides, what we know, what is normal, what is rational, what is desirable, etc. What the law provides in a world is a set of propositions $\mathrm{p}$ such that the law provides that $\mathrm{p}$ in that world. The denotation of what the law provides is then the function that assigns to every possible world this set of propositions $\mathrm{p}$. More generally, a conversational background is a function $\mathrm{f}$ which assigns sets of propositions to possible worlds.

The modal base is defined as a set of worlds determined by a conversational background $\mathrm{f}$. The set of worlds in which all propositions of $\mathrm{f}(\mathrm{w})$ are true constitutes the modal base in $\mathrm{w}$. The modal base thus determines the set of worlds accessible from each world.

The ordering source is a second conversational background $g$ which assigns to every possible world a set of propositions. Ordering sources represent ideals, given that they can induce an ordering on the modal base (the worlds in the modal base may be closer or further away from what the law provides, what is desirable, what is normal, etc.).

More generally, a set of propositions A can induce an ordering $\#_{\mathrm{A}}$ on a set of worlds $\mathrm{W}$ in the following way (following Lewis 1981).

The ordering $\#_{\mathrm{A}}$ :

$\mathrm{W}, \mathrm{W}=0 \mathrm{~W}: \mathrm{w}_{\mathrm{A}} \mathrm{W}=$ iff $\{\mathrm{p}: \mathrm{p} 0 \mathrm{~A}$ and $\mathrm{w}=0 \mathrm{p}\} \phi\{\mathrm{p}: \mathrm{p} 0 \mathrm{~A}$ and $\mathrm{w} 0 \mathrm{p}\}$

$>\mathrm{A}$ world $\mathrm{w}$ is at least as close to the ideal represented by $\mathrm{A}$ as a world $\mathrm{w}=$ iff all propositions of $\mathrm{A}$ which are true in $\mathrm{w}=$ are true in $\mathrm{w}$ as well.=

Thus, in (44), worlds are ordered with the help of an unordered set of propositions. A world w is at least as close to the ideal represented by $\mathrm{A}$ as a world $\mathrm{w}=$ iff it makes at least as many propositions true as $\mathrm{w}=$ does.

Sentences containing modals are then evaluated with respect to an ordered set of worlds. The ordering source is usually not expressed explicitly in the sentence but has to be recovered from the context. Consider the following example in (45).

(45) Sofía should bring a chocolate cake. 
In the context of the scenario discussed previously, in section 4.1, the modal base of this sentence is formed by the set of worlds that constitute Victoria $=\mathrm{s}$ beliefs. The ordering source is bouletic and corresponds to the set of propositions determined by Victoria $=\mathrm{s}$ desires. This set of propositions induces an ordering on the set of the modal base. The modal force of the modal should is necessity. The meaning of (45) can then be paraphrased as in (46).

(46) In view of what Victoria desires, it is necessary for Sofía to bring a chocolate cake.

We now turn to the implementation of a semantics based on modal necessity for predicates that select the subjunctive mood.

Giorgi and Pianesi (1997) propose that the contexts in which the subjunctive mood appear can be characterized with the semantics that Kratzer proposes for modal expressions. The generalization they propose is that in certain Romance languages such as Spanish and French, the subjunctive mood is selected when the context requires the interaction between a modal base and a non-null ordering source. This generalization still does not tell us what exactly the semantics should be for the predicates that select the subjunctive mood. Giorgi and Pianesi do not explicitly formalize a proposal for the semantics of these predicates, but only illustrate the kind of semantics they want to use with the modal must. I will thus follow here instead von Fintel (1999), who proposes to adopt a semantics of modal necessity for propositional attitude predicates such as want, wish, be glad and be sorry. He defines the following concepts.

(47) (i) The $>$ modal base function $=\mathrm{f}$ is a function from pairs of an individual and a world to a set of worlds.

(ii) The > ordering source function = is a function from pairs of an individual and a world to a set of propositions (in the case of want to a set of propositions forming the subject $=\mathrm{s}$ preferences).

(von Fintel 1999, p.115)

Here, the subject $=\mathrm{s}$ preferences form an unordered set of propositions that induce an ordering on the modal base. The best worlds are those that make most propositions true. This is stated in the following definition. 
For any set of propositions $\mathrm{P}$, we define a strict partial order $<_{\mathrm{P}}$ :

$$
\mathrm{W}=, \mathrm{W}==:\left(\mathrm{w}=<_{\mathrm{P}} \mathrm{W}==\text { iff } \quad \mathrm{p} 0 \mathrm{P}(\mathrm{w}==0 \mathrm{p} 6 \mathrm{w}=0 \mathrm{p}) \& \quad \mathrm{p} 0 \mathrm{P}\left(\mathrm{w}=0 \mathrm{p} \& \mathrm{w}==\int \mathrm{p}\right)\right)
$$

(Von Fintel 1999, p. 115)

Von Fintel proposes to use the selection function $\max _{\mathrm{P}}$ that selects the best worlds in any set $\mathrm{X}$ with respect to a partial order $<_{\mathrm{P}}$, as defined in (49).

(49) For a given strict partial order $<_{\mathrm{P}}$ on worlds, define the selection function $\max _{\mathrm{P}}$ that selects the set of $<_{\mathrm{P}}$-best worlds from any set $\mathrm{X}$ :

$\mathrm{X} \phi \mathrm{W}: \max _{\mathrm{P}}(\mathrm{X})=\left\{\mathrm{w} 0 \mathrm{X}: 5 \quad \mathrm{w}=0 \mathrm{X}: \mathrm{w}=<_{\mathrm{P}} \mathrm{w}\right\}$

(von Fintel 1999, p.116)

The semantics of the verb want can then be stated as in (50), as proposed in von Fintel (1999). The proposition is here evaluated in those worlds in the modal base $f(\alpha, w)$ that maximally satisfy the preferences given by the ordering source $g(\alpha, w)$. Thus, the ordering source is used to induce an ordering on the worlds in the modal base.

\section{Semantics of modal necessity for want}

$$
\text { want }^{\mathrm{f}, \mathrm{g}}(\mathrm{p})(\alpha)(\mathrm{w})=\text { true iff } \quad \mathrm{w}=0 \max _{\mathrm{g}(\alpha, \mathrm{w})}(\mathrm{f}(\alpha, \mathrm{w})): \mathrm{w}=0 \mathrm{p} .
$$

$>$ Among the worlds $f(\alpha, w)$, the ones that maximally correspond to $\alpha=$ s preferences in $w$ are all $p$-worlds $=($ von Fintel 1999, p.115 $)$

Von Fintel proposes that the verb want requires the modal base $\mathrm{f}$ to be formed by the worlds that are compatible with the subject=s beliefs. The ordering source $g$ is formed by the set of the subject $=$ s desires. In other words, in (50), $\alpha$ wants $\varphi$ is true in $\mathrm{w}$ iff among the worlds compatible with $\alpha=$ s beliefs, the ones that maximally correspond to $\alpha=\mathrm{s}$ desires in $\mathrm{w}$ are all $\varphi$-worlds.

Thus, this semantics is identical to the semantics of the predicate should. The only difference is that, in the case of the modal should the ordering source is contextually determined, while in the lexical entry provided here for want the ordering source is explicitly introduced by the verb. 
Such a semantics can easily be extended to the other propositional attitude predicates that select the subjunctive mood in Spanish. There are two types of parameters of variation that we expect. First, the modal base should differ from predicate to predicate: predicates such as wish and be glad require a modal base formed by the set of revised doxastic alternatives. Second, the ordering source also varies from predicate to predicate. For example, for predicates such as want and wish the ordering is determined by the desires of the subject, while for predicates such as be surprised and doubt the ordering is determined by what the subject considers likely.

Von Fintel=s proposal is modeled after the semantics of modals that express necessity, such as must and should. In (50), it is required that the proposition expressed by the complement clause be necessarily true in all the worlds that maximally correspond to $\alpha=$ s desires (the worlds selected by the function $\max _{\mathrm{P}}$ ). Let us now consider the option that some of the predicates under discussion may also be modeled after the semantics of modals that express possibility, such as may and could.

Kiefer (1987) proposes that the semantics of different kinds of propositional attitudes involves both modal necessity and modal possibility. One may then adopt the view that different propositional attitude predicates may encode different kinds of modal strength.

To adopt modal possibility for the semantics of a predicate, only a few simple modifications from the previous proposal are necessary. Following Kratzer (1991), a proposition p is a possibility in a world w with respect to a modal base $\mathrm{f}$ and an ordering source $\mathrm{g}$ iff $5 \mathrm{p}$ is not a necessity in w with respect to f and g. (Kratzer 1991, p. 644). Hence, instead of requiring that the proposition p be true in all worlds selected by the max-function (the worlds that maximally correspond to the subject=s preferences), we require that there is a world among those selected by the max-function such that $\mathrm{p}$ is true in that world. 
I propose to illustrate this kind of semantics with the predicate be disappointed. For a predicate such as be disappointed, there are indeed situations in which $\alpha$ is disappointed that $p$ in $w$ is true even if $\mathrm{p}$ is not true in all worlds that maximally correspond to what $\alpha$ considers undesirable in $\mathrm{w}$, as illustrated previously with example (31). A semantics of necessity is thus not appropriate for this predicate: AVictoria is disappointed that Sofía brought an apple piee can be considered true in a scenario where ASofia brought an apple piee is not true in all worlds that maximally correspond to what Victoria considers undesirable. One may then consider to adopt a semantics of possibility, as presented in the lexical entry below.

\section{(51) Semantics of modal possibility for be disappointed}

$$
\text { be disappointed }^{\mathrm{f}, \mathrm{g}}(\mathrm{p})(\alpha)(\mathrm{w})=\text { True iff } \quad \mathrm{w}=0 \max _{\mathrm{g}(\alpha, \mathrm{w})}(\mathrm{f}(\alpha, \mathrm{w})): \mathrm{w}=0 \mathrm{p} \text {. }
$$

In the case of the predicate be disappointed, the ordering source $\mathrm{g}$ is determined by what is considered undesirable by $\alpha$ in $\mathrm{w}$. The modal base $\mathrm{f}$ is the set of worlds compatible with $\alpha=\mathrm{s}$ revised beliefs. (51) then says that $\alpha$ is disappointed that $p$ in $w$ is true iff among the worlds $\mathrm{f}(\alpha, \mathrm{w})$ compatible with $\alpha=\mathrm{s}$ revised beliefs, there is a world $\mathrm{w}=$ in the set of worlds that maximally correspond to what $\alpha$ considers undesirable in $\mathrm{w}$ such that $\mathrm{p}$ is true in that world $\mathrm{w}=$.

To conclude, in this section I have presented a semantics for the predicates that select the subjunctive mood based on modal necessity and modal possibility that is identical to the semantics commonly adopted for the modals must and can. In the following, I investigate a few characteristics of the predicates that select the subjunctive mood in Spanish that present difficulties to such an approach. I will argue that my proposal based on comparison of contextual alternative propositions can accommodate these characteristics in a more straightforward way. 


\subsection{Comparing the predictions}

In this section, I argue that there are some empirical differences between a semantics for the predicates selecting the subjunctive mood that is modeled after modal necessity/possibility and the semantics of comparison that I developed in section 4. In the following, I present several facts related to practical inferences, possible rankings of the alternatives, lack of entailment relations, and association with focus phenomena. I discuss the predictions of the different proposals concerning these phenomena. We will see that these phenomena can be straightforwardly accommodated within the semantics of comparison developed here.

\subsubsection{Practical Inferences}

With the help of practical inferences (Von Wright (1963)), I will argue that a semantics of modal necessity or possibility cannot straightforwardly capture an important property of the predicates that select the subjunctive mood.

Below, I present an example that shows that, in the conclusion of certain practical inferences, we cannot replace the modal verb (which expresses necessity) with the predicate want. Under the assumption that both predicates are analyzed with a semantics of modal necessity (i.e. that they essentially have the same semantics), we however expect that this should be possible. From the two premisses a) and b) we can infer c). Yet, we cannot infer d).

(52) a) Marcela wants to go to the picnic.

b) Marcela believes that she can only go to the picnic if she works extra hours.

c) Marcela should work extra hours.

d) Invalid inference:

Marcela wants to work extra hours.

I now show that under the assumption that want receives a semantics of modal necessity, we predict that d) should be a valid inference, just like c). I repeat here von Fintel=s proposal for the semantics of want discussed earlier. 


\section{Semantics of modal necessity for want}

$$
\text { want }^{f, g}(p)(\alpha)(w)=\text { True iff } \quad w=0 \max _{g(\alpha, w)}(f(\alpha, w)): w=0 p \text {. }
$$

By using the semantics for want as stated in (53), we predict the following for the example (52). From a) it follows that among the worlds compatible with Marcela $=\mathrm{s}$ beliefs, the ones that maximally correspond to her desires in $w$ are all worlds in which she goes to the picnic. From b) it follows that Marcela believes that all worlds in which she goes to the picnic are worlds in which she works extra hours. We can thus infer that among the worlds compatible with Marcela=s beliefs the ones that maximally correspond to her desires in w are all worlds in which she works extra hours, and we expect d) to be true. (53) thus predicts that d) should be a possible inference from a) and b), contrary to what is observed.

Among the predicates that select the subjunctive mood, there are a number of predicates that do not allow for such practical inferences, such are preferir (prefer), temer ( $>$ fear=), esperar $(>$ hope $=)$, alegrarse $(>$ be $\mathrm{glad}=)$, lamentarse $(>$ regret $=)$, sugerir $(>$ suggest $=)$, recomendar ( $>$ advise $=$ ), sorprenderse ( $>$ be surprised $=$ ) and dudar $(>\mathrm{doubt}=$ ).

To conclude, practical inferences provide an argument against a semantics of modal necessity. To the contrary, a semantics based on comparison of contextual alternatives captures the phenomenon in a straightforward way: in my proposal there is no expectation that the inference should also hold for the predicate want.

\subsubsection{Lack of entailment relations}

An interesting characteristic of the predicates under discussion is that entailment relations between propositions do not survive when these propositions are embedded under the predicates, as has been previously observed in Katz (1991), Kadmon and Landman (1993), Lee \& Horn (1994), Linebarger (1987) von Fintel (1999), and others. Thus, when a proposition $p$ entails a proposition $q$, this does not necessarily have the consequences that $\alpha$ is glad that $p$ entails that $\alpha$ is glad that $q$.

The fact that entailment relations between propositions do not survive in this context is problematic for a semantics based on modal necessity. This can be shown with an example discussed in Kadmon \& Landman (1993) and von Fintel (1999). 
(54) He bought a Honda.

(55) He bought a car.

(56) I am glad he bought a Honda.

(57) I am glad he bought a car.

The proposition in (54) entails the proposition in (55), given that all the worlds in which he bought a Honda are worlds in which he bought a car. Nevertheless, when these propositions are embedded under the predicate be glad, we do not find an entailment relation: the proposition in (56) does not entail the proposition in (57). This is so, since all the worlds in which I am glad that he bought a Honda are not necessarily worlds in which I am glad that he bought a car. The sentence in (56) can very well be true in a situation in which I am not glad at all that he bought a car. I may in fact be upset about it and think that for environmental reasons it would have been much better for him to buy a bike. But given that he has bought a car, I am glad that he bought a Honda rather than another car. Maybe the Honda is not as polluting a choice as the other options would have been.

To show that a semantics of modal necessity cannot capture this lack of entailment relations, I repeat here the corresponding lexical entry for the predicate be glad.

\section{Semantics of modal necessity for be glad}

$$
\text { be } \operatorname{glad}^{\mathrm{f}, \mathrm{g}}(\mathrm{p})(\alpha)(\mathrm{w})=\text { True iff } \quad \mathrm{w}=0 \max _{\mathrm{g}(\alpha, \mathrm{w})}(\mathrm{f}(\alpha, \mathrm{w})): \mathrm{w}=0 \mathrm{p} .
$$

In the lexical entry for be glad, f stands for a modal base that contains all the worlds that are compatible with the subject $=$ s revised beliefs and $g$ stands for an ordering source that is determined by the subject=s desires. For the sentence pair in (56) and (57) then the following holds. If the sentence in (56) is true, we predict that among the worlds compatible with my revised beliefs, the ones that maximally correspond to my preferences in w are all worlds in which he bought a Honda. All the worlds in which he bought a Honda are also worlds in which he bought a car. Hence, we can conclude that among the worlds compatible with my revised beliefs, the ones that maximally correspond to my preferences in $\mathrm{w}$ are all worlds in which he bought a car. Thus, with the semantics in (58), whenever the sentence in (56) is true, the sentence in (57) is true as well. As a consequence, a semantics of modal necessity cannot capture the lack of entailment relations. 
The problematic aspect of a semantics based on modal necessity is that it requires to verify whether $\mathrm{p}$ is true in all the worlds that best fit $\alpha=\mathrm{s}$ desires. If in all those worlds it is true that he bought a Honda, automatically it is also true that in all those worlds he bought a car. However, we have seen that the entailment does not necessarily hold: if I am glad that he bought a Honda it does not necessarily hold that I am also glad that he bought a car.

To remedy this problem, Kadmon and Landman (1993) suggest that for predicates such as be glad there is another contextually interpreted modal parameter involved, a so-called perspective. The perspective enters into the semantics of these predicates and affects the truth conditions of sentences containing it. This would explain why it is possible for me to be glad that he bought a Honda (because a Honda is a better choice than other cars), and at the same time not be glad that he bought a Honda (because I have something against buying cars), without contradicting myself. Kadmon and Landman (1993) claim that entailment relations are maintained unless the perspective changes. However, they do not present an explicit proposal as to how this perspective is to be incorporated into a semantics of predicates such as be glad. We will see that the proposal that I have developed here provides us with the means to make this notion more explicit. Under my proposal, a change in perspective simply corresponds to a change in the set of alternative propositions.

Von Fintel (1999) suggests that a semantics of modal necessity can still be maintained. He proposes that, for the two examples (56) and (57), there is a shift in which worlds are being considered, because they assume different contexts. For the example (56), only worlds in which he bought a car are compared. For different sentences, the modal base then would not always be the same, rather it would be contextually determined. Under this assumption, we do not expect there to be an entailment relation between the two sentences. He thus proposes that the phenomenon under discussion is explained by the fact that there may be a contextually signaled narrowing of the modal base relevant for the interpretation of the predicate. A semantics of modal necessity can thus be amended to capture the fact if we allow the modal base to change with the context.

One of my main goals has exactly been to show this last point, namely, that for different examples, different contextual alternatives are relevant. At the core of my proposal is the idea that contextual alternatives are an important ingredient of the semantics of these predicates. By employing a semantics of comparison of contextual alternatives for the predicate be glad we do not expect that an entailment relation should hold between the two examples (59) and (60), repeated from before. 
(59) I am glad he bought a Honda.

(60) I am glad he bought a car.

In my proposal, no entailment relation is expected, since the set of contextual alternatives differs for both examples. In the example in (59), the set of alternatives could be $\{$ He bought a Honda, He bought a Toyota, He bought a Mercedes $\}$, while in the example in (60), this set could be $\{\mathrm{He}$ bought a car, He bought a bike, He didn=t buy anything $\}$. Thus, we do not expect that (59) entails (60).

Kadmon and Landman=s notion of perspective can then be characterized with the help of the set of alternatives. A change in perspective corresponds to a change of the set of alternatives. Similarly, a change in the modal base in von Fintel=s account, corresponds to a change in the set of alternatives.

\subsubsection{Possible rankings of the alternatives}

Predicates such as be glad, be disappointed and regret illustrate that $\mathrm{p}$ is not always necessarily the best/worst alternative. In certain contexts, $\alpha$ is glad that $p$ is true in $w$ even if $p$ is not true in the worlds that best match $\alpha=\mathrm{s}$ desires. We can illustrate this again with the previous scenario that has more than two alternatives. I repeat the schematic figure below.

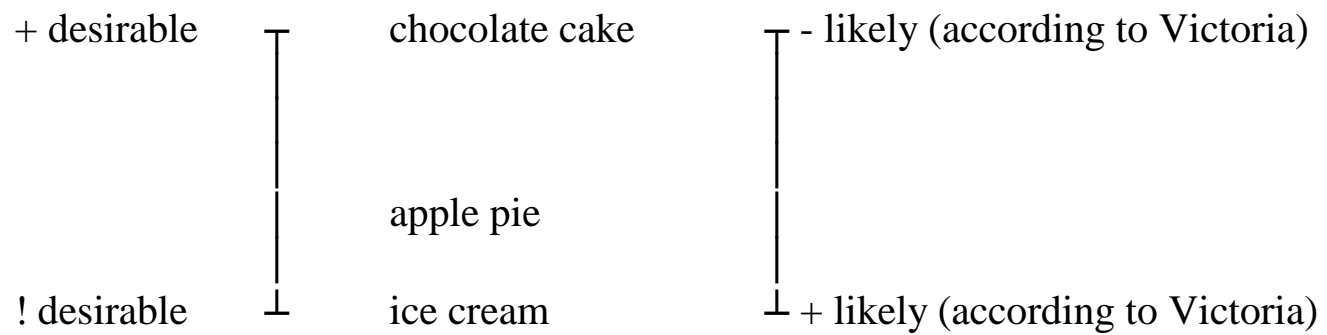

Imagine, that Sofía in the end brought an apple pie. Then, the sentence in (62) can be true in this scenario:

(62) Victoria is glad that Sofía brought an apple pie. 
Victoria may be glad that Sofia at least didn=t bring ice cream, which she would have hated. Thus, the sentence in (62) is true in a scenario in which p is not the best alternative. It would have been much better for Victoria if Sofía had brought a chocolate cake.

By employing a semantics of modal necessity, we however predict that this sentence should be false in this scenario. A semantics of modal necessity for the predicate be glad is given in (63).

\section{Semantics of modal necessity for be glad}

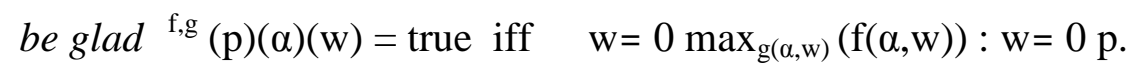

The lexical entry of be glad in (63) predicts that the example (62) should be false in this scenario. It requires that among the worlds compatible with Victoria=s revised beliefs (the modal base f), the ones that maximally correspond to Victoria=s preferences in w are all worlds in which Sofía brings an apple pie. But, in fact, Victoria would have preferred it if Sofía had brought a chocolate cake. Thus, in none of the worlds that best match Victoria=s preferences it is the case that she brings an apple pie. Hence, a semantics of modal necessity makes the wrong prediction for predicates such as be glad.

Let us now see whether a semantics of modal possibility could better capture the truth conditions of the predicate be glad. The lexical entry of the predicate be glad is then as in (64).

\section{(64) Semantics of modal possibility for be glad}

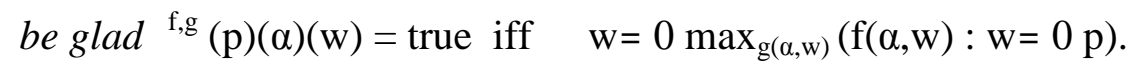

This semantics of the predicate be glad does not make the correct predictions for the above scenario either. The meaning of be glad expressed in (64) predicts that the example (62) should be false in the given scenario. The lexical entry requires that there is a world among the worlds that best match Victoria $=$ s desires such that Sofía brings an apple pie in that world. Nevertheless, we already saw before that this is false: since Victoria prefers the chocolate cake, all worlds that maximally correspond to her preferences are worlds in which Sofía doesn=t bring an apple pie, but rather a chocolate cake.

Hence, we have seen that neither modal necessity nor modal possibility can capture the fact that, for certain predicates, $\mathrm{p}$ may not necessarily be the best alternative. The problem with this kind 
of semantics is that we only consider worlds that best match the subject=s desires. But these may sometimes in fact be irrelevant.

To the contrary, the proposal that I have developed so far can capture the truth conditions of a predicate such as be glad, because it allows to express that $\mathrm{p}$ is not necessarily the best alternative. The predicates under discussion seem to vary with respect to this issue. Some predicates, such as prefer, for example, require $\mathrm{p}$ to be ranked highest among the alternatives, whereas other predicates such as be glad and regret don=t. This information should then be encoded in the lexical entry of these predicates. The lexical entry for be glad could be formalized as in (65).

\section{Semantics based on comparison of alternatives for be glad}

$$
{\text { be } \operatorname{glad}_{C}}^{\mathrm{g}}(\mathrm{p})(\mathrm{a})(\mathrm{w})=1 \text { iff } \mathrm{q}: \mathrm{q} \quad \mathrm{p} \& \mathrm{q} 0 \mathrm{~g}(\mathrm{C}): \mathrm{p}>\text { Desa,w } \mathrm{q}
$$

This lexical entry for the predicate be glad does not require that $\mathrm{p}$ be the best alternative, but rather that there be an alternative $\mathrm{q}$ such that $\mathrm{p}$ is more desirable than $\mathrm{q}$. In this scenario, we predict the sentence Victoria is glad that Sofía brought the apple pie to come out as true: there is an alternative ( $>$ Sofía brings ice cream $=$ ) such that the alternative $>$ Sofía brings an apple pie $=$ is more desirable.

To conclude, we have seen that a semantics based on necessity or possibility cannot capture the fact that certain predicates such as be glad do not require the proposition expressed by the complement clause to be ranked highest. A semantics based on comparison of contextual alternatives leaves room for variation in this domain. Different kinds of constraints on how the proposition $p$ stands with respect to the other alternatives can be implemented.

In Kratzer (1991), next to modal possibility and necessity, other modal strengths are also defined, among which the modal strength of at least as good a possibility and better possibility. Let me now show in what respect my proposal differs from Kratzer=s proposal on comparative possibility, which is based on the interaction of a modal base with an ordering source:

Definition 9 (Kratzer 1991:p644)

A proposition $\mathrm{p}$ is at least as good a possibility as a proposition $\mathrm{q}$ in a world $\mathrm{w}$ with respect to a modal base $\mathrm{f}$ and an ordering source $\mathrm{g}$ iff for all $\mathrm{u}$ such that $\mathrm{u} 01 \mathrm{f}(\mathrm{w})$ and $\mathrm{u} 0 \mathrm{q}$ there is a v $01 \mathrm{f}(\mathrm{w})$ such that $\mathrm{v}_{\mathrm{g}(\mathrm{w})} \mathrm{u}$ and $\mathrm{v} 0 \mathrm{p}$. 
Definition 10 (Kratzer 1991: p.644)

A proposition $\mathrm{p}$ is a better possibility than a proposition $\mathrm{q}$ in a world $\mathrm{w}$ with respect to a modal base $\mathrm{f}$ and an ordering source $\mathrm{g}$ iff $\mathrm{p}$ is at least as good a possibility as $\mathrm{q}$ and $\mathrm{q}$ is not at least as good a possibility as $\mathrm{p}$ in $\mathrm{w}$ with respect to $\mathrm{f}$ and $\mathrm{g}$.

The notion of better possibility is defined here for propositions $\mathrm{p}$ and $\mathrm{q}$ with respect to a modal base $\mathrm{f}$ and an ordering source g. The ordering source corresponds to an unordered set of propositions that induces an ordering on the relevant set of worlds in the modal base. Crucially, in this definition, the propositions $p$ and $q$ to be compared are not part of the set of propositions that forms the ordering source. Hence, we could not assume, as was previously done in von Fintel=s proposal for the predicate $w a n t$, that the ordering source contains those propositions that correspond to the subject=s preferences (since, at least in the case of the predicate want, the proposition $\mathrm{p}$ and $\mathrm{q}$ to be compared are presumably propositions that express the subject=s desires).

In my proposal, the set of contextual alternative propositions is not used to induce the ordering. Rather, the different propositions expressing the desires of Victoria are ranked with respect to an ordering relation or scale. Thus, the crucial difference between the two approaches is that in one case the propositions that express the desires are unordered while they are ranked with respect to a scale in the other.

As pointed out to me by Barbara Partee, in the approach that uses ordering sources, one may express ranked desires by using a set of disjunctions as the relevant ordering source. For our scenario, we would need the set $\{>$ Sofía brings a chocolate cake $=,>$ Sofía brings a chocolate cake or apple pie $=,>$ Sofía brings a chocolate cake or apple pie or ice cream $=\}$. Given such an ordering source, the best worlds are then the worlds in which Sofía brings the chocolate cake: these are the only worlds that make all three propositions true. If it seems plausible to use ordering sources of this kind, these two approaches may turn out to be equivalent.

In the following section, however, I will show that the proposal developed here has two advantages. Given that predicates are analyzed parallel to focus sensitive operators such as only, we predict these predicates to be focus sensitive. In section 7.1, I show that this prediction is born out. The Kratzer-style approach, which is based on the interaction of a modal base with an ordering source, however, does not make this prediction. In section 7.2.1, I argue that the subjunctive mood morpheme makes a particular semantic contribution, namely that it evaluates the contextual 
alternatives for the matrix predicate. In the Kratzer-style semantics, there does not seem to be room for such a semantic contribution: the subjunctive mood morpheme would simply have to make a vacuous semantic contribution. Hence, the proposal developed here has the advantage of providing a first step towards a better understanding of the question why subjunctive verb forms are obligatory under the predicate classes discussed here.

\section{Mood and Focus}

In this section, I turn to investigating an important consequence of my proposal. Given the analysis presented here, we expect the predicates that select the subjunctive mood to be focus sensitive. The focus sensitivity of these predicates follows directly from the fact that they are analyzed analogous to other focus sensitive operators such as only. We thus expect the meaning of these predicates to be affected by a focused constituent in the embedded clause.

\subsection{Focus sensitive predicates}

As already pointed out in Dretske $(1972,1975)$, focused phrases embedded under certain propositional attitude predicates give rise to meaning differences. In the context of the previous picnic scenario, the sentence in (68) is felicitous, while the sentence in (69) is not (words in capital are focused).

(68) Victoria wants Sofia to bring A CHOCOLATE CAKE.

(69) Victoria wants SOFIA to bring a chocolate cake.

The proposal developed here can provide a rather straightforward analysis of the meaning difference between examples (68) and (69). This theory makes explicit that for predicates such as want an analogy to focus sensitive operators such as only is expected. Both want and only make reference to a domain of quantification $\mathrm{C}$ of contextually determined alternatives, which following. Rooth (1992) is constrained by focus.

In fact, Rooth $(1985,1992)$ shows that focus has a truth conditional effect in the context of the adverb only. He presents the following example: in a context in which Mary introduced Bill and Tom 
to Sue and there were no other introductions, (70) is true, but (71) is false. These two sentences only differ in terms of what constituent is focused (marked in capital letters).

(70) Mary only introduced Bill to SUE.

(71) Mary only introduced BILL to Sue.

For the predicates discussed here, we thus also predict differences in focus structure in the embedded clause to have a truth conditional effect. In this section, my goal is to show that, while predicates that select the subjunctive mood do show this effect, predicates that select the indicative mood do not.

We begin with the class of desire predicates. I illustrate their behavior with the predicate want and use some examples similar to the one discussed in Heim(1992). Consider the following context:

(72) In the linguistics department, at the faculty meeting, the teaching schedules of the different faculty members for the upcoming semester are discussed. There is only one syntactician in the department (John), one phonologist (Lisa), and two semanticists (Lara and Frank). John can only teach syntax. Lara can teach syntax and semantics. There is some controversy on which days John should teach his syntax classes. There are two options: he may teach syntax on Tuesdays and Thursdays, or he may teach syntax on Mo, We \& Fri. Lisa=s preferences are the following: she would prefer it if Lara would teach syntax rather than John. But given that John has to teach syntax, she prefers it if he teaches on Tuesdays and Thursdays rather than on Mo, We \& Fri (because she wants the teaching slot on Mo, We \& Fri for her own phonology class, which cannot conflict with the syntax class).

In this scenario, consider the following utterances:

(73) Lisa wants John to teach syntax ON TUESDAYS AND THURSDAYS.

(74) Lisa wants JOHN to teach syntax on Tuesdays and Thursdays. 
In the described scenario, the utterance in (73) is true. However, the utterance in (74) cannot be true (since Lisa would in fact prefer it if Lara would teach syntax, not John). The only difference between these two utterances is that a different constituent is focused in the embedded clause.

We can thus conclude that, in the presence of the predicate want, the focus structure of the embedded clause has a truth conditional effect. The same can be shown to hold for other predicates that select the subjunctive mood in Spanish. For the class of emotive factive predicates, I illustrate this with the predicate be glad.

In the context described above, assume that, at the end of the faculty meeting, it is decided that John is indeed going to teach syntax on Tuesdays and Thursdays. Consider now the following utterances.

(75) Lisa is glad that John teaches syntax ON TUESDAYS AND THURSDAYS.

(76) Lisa is glad that JOHN teaches syntax on Tuesdays and Thursdays.

Here again, (75) can be true in the described scenario, but not (76) (for the same reasons as before). The predicate be glad can thus be considered to be focus sensitive.

Boer(1978) illustrates that this same kind of focus sensitivity also appears in conditional sentences. He presents an example introduced by Dretske(1972) with the following scenario: Ted=s father left a clause in his will stipulating that Ted can only receive his inheritance if he is married by a certain date. In this context (77) is true, but (78) is false:

(77) If Ted hadn=t MARRIED Alice, he would have lost his inheritance.

(78) If Ted hadn=t married ALICE, he would have lost his inheritance.

Similarly, the causative predicate cause and the directive predicate demand $^{10}$, which in Spanish select the subjunctive mood, show focus sensitivity. Modeling our examples after the conditional sentences, in the same context, the examples (79) and (81) are true, while (80) and (82) are false:

(79) His father caused Ted to MARRY Alice.

(80) His father caused Ted to marry ALICE.

${ }^{10}$ See also Dretske(1975), p.415, for an example which illustrates that directive predicates such as $>$ advise $=$ are focus sensitive. 
(81) His father demanded that Ted MARRY Alice.

(82) His father demanded that Ted marry ALICE.

Notice that a modal predicate such as be necessary also displays this pattern: in the same context, (83) is true while (84) is false :

(83) In order to receive his inheritance, it was necessary that Ted MARRY Alice.

(84) In order to receive his inheritance, it was necessary that Ted marry ALICE.

We have thus seen examples for each predicate class that selects the subjunctive mood (desire predicates, emotive factives, modals, directives and causatives) that show that the matrix predicate is sensitive to the focus-structure of the embedded clause.

In contrast, consider now some examples containing predicates that select the indicative mood in Spanish. The following examples contain the epistemic predicate know.

\section{Lisa knows that John teaches syntax ON TUESDAYS AND THURSDAYS.}

Lisa knows that JOHN teaches syntax on Tuesdays and Thursdays.

Contrary to the previous examples, here the matrix predicate does not seem to be sensitive to the focus structure of the embedded clause. These examples are both true under the same circumstances: all contexts that make one of them true make the other one true as well. The fact that the predicate know is not focus sensitive can best be illustrated with a dialogue. If speaker A says: ALisa knows that John teaches syntax ON TUESDAYS AND THURSDAYS.@, speaker B cannot reply ANo, that=s not true. Lisa knows that JOHN teaches syntax on Tuesdays and Thursdays.@ without contradicting himself. Notice that this is different for the predicate want. If speaker A says: ALisa wants John to teach syntax ON TUESDAYS AND THURSDAYS.@, speaker B can than naturally reply ANo , that $=\mathrm{s}$ not true. Lisa wants JOHN to teach syntax on Tuesdays and Thursdays.@ without uttering a contradiction $^{11}$.

\footnotetext{
${ }^{11}$ For some speakers, a more explicit context is necessary to make this a natural dialogue. For example speaker B could naturally reply: "well, that's not really true, as she doesn't mind which day these classes take place, as long as
} 
Other predicates that select the indicative mood, such as predicates of communication are not focus sensitive either, as can be illustrated with the predicate say:

Lisa said that John teaches syntax ON TUESDAYS AND THURSDAYS.

Lisa said that JOHN teaches syntax on Tuesdays and Thursdays.

In these examples, focus on a constituent in the embedded sentence creates alternatives that are not evaluated by the predicate of the matrix clause: the alternatives that are available for an example such as (87) are the alternatives to the whole clause, not the embedded clause: > Lisa said that John teaches syntax on Tuesdays and Thursdays $=$ and $>$ Lisa said that John teaches syntax on Mondays, Wednesdays and Fridays $=$. Similarly, in (88), the available alternatives are $>$ Lisa said that John teaches syntax on Tuesdays $\&$ Thursdays $=$ and $>$ Lisa said that Lara teaches syntax on Tuesdays and Thursdays $=$.

It can easily be shown that the same holds for other predicate classes that select the indicative mood in Spanish: predicates of certainty (e.g. estar convencido $>$ be convinced $=$, estar seguro $>$ be certain $=$ ), commissives ( rometer $>$ promise $=$ ), and fiction predicates (e.g. soñar $>$ dream $=$ ) have this same property.

In fact, in the literature, some examples have already been provided to show that focus does not always have the same effect in the context of all propositional attitude predicates. The following examples are from Boër (1979). He suggests that with predicates such as know and believe the meaning differences induced by focused constituents in the complement clause are much less perceptible.

(89) Tom knows/believes that Bob HIT Alice.

(90) Tom knows/believes that Bob hit ALICE.

Similarly, Dretske (1972) points out that predicates such as believe and say are not sensitive to the contrastive differences of the embedded clause (see footnote 16, p.435).

John is the one who does the teaching, so one should rather say that Lisa wants JOHN to teach syntax on tuesdays and thursdays." (personal communication, Jenny Doetjes). 
Finally, let me illustrate with the example of the predicate sentir which can select both the subjunctive and indicative mood, that such predicates are only focus sensitive when they select the subjunctive mood. The predicate sentir, when it selects the subjunctive mood, has the meaning of the emotive factive predicate $>$ be sorry $=$. In the scenario above, (91) turns out to be false, while (92) is true:

(91) Lisa siente que Juan de clases de sintaxis los MARTES Y JUEVES

$>$ Lisa is sorry that Juan teaches syntax on TUE\&THUR=

(92) Lisa siente que JUAN de clases de sintaxis los martes y jueves

$>$ Lisa is sorry that JUAN teaches syntax on Tue\&Thur=

To the contrary, when the predicate has the meaning of $>$ sense $=/=$ have the impression $=$, and selects the indicative mood, the two examples (93) and (94) are truthconditionally equivalent:

(93) Lisa siente que Juan dará clases de sintaxis los MARTES Y JUEVES

$>$ Lisa has the impression that Juan will teach syntax on TUE\&THUR=

(94) Lisa siente que JUAN dará clases de sintaxis los martes y jueves

$>$ Lisa has the impression that JUAN will teach syntax on Tue\&Thur=

To conclude, the purpose of this section has been to argue that predicates that select the subjunctive mood are sensitive to the presence of a focused constituent in the embedded clause: when different constituents are focused, there is a truth conditional meaning difference. We thus have evidence for the claim that the predicates that select the subjunctive mood are focus sensitive operators.

In the following section, I turn to making precise what the semantic contribution of the subjunctive mood morpheme is.

\subsection{The semantic contribution of the subjunctive mood}


In this section, I address the following question: what role does the subjunctive mood morpheme play in the semantic composition of the sentence? The literature on the semantics of mood rarely addresses this question. The main focus of the majority of previous studies has rather been to provide a characterization of the contexts in which the subjunctive mood appears. The investigation of what the subjunctive mood contributes to the meaning composition provides a first step towards a better understanding of why subjunctive verb forms require special semantic licensing conditions and why they are obligatory in certain contexts.

To begin, I introduce Rooth=s $(1985,1992)$ terminology for the semantics of sentences containing focused constituents and present his semantics for focus sensitive operators such as only.

\subsubsection{Focus according to Rooth $(1985,1992)$}

As mentioned before, Rooth $(1985,1992)$ shows that focus has a truth conditional effect in the context of the adverb only. I now present Rooth=s proposal for the meaning of sentences of the following kind:

(95) Mary only introduced Bill to SUE.

(96) Mary only introduced BILL to Sue.

In Rooth $(1985,1992)$, next to the ordinary semantic value, an additional semantic value is used to express the contribution that focus makes to the meaning of a sentence. The focus semantic value of a constituent $\alpha$ is represented as $\quad \alpha$ ALT, its ordinary semantic value as $\alpha_{0}$. The focus semantic value of a sentence is the set of propositions obtainable from the ordinary semantic value by making a substitution in the position corresponding to the focused phrase. I present here the ordinary and alternative semantic values for the sentences above without only.

(97) Mary introduced Bill to $[\text { Sue }]_{\mathrm{F}}$ o $=\lambda \mathrm{w}$.Mary introduced Bill to Sue in $\mathrm{w}$

(98) Mary introduced Bill to $[\text { Sue }]_{\mathrm{F}}$ ALT $=\{\lambda w$.Mary introduced Bill to $\mathrm{x}$ in w/x $0 \mathrm{D}\}$

(99) Mary introduced $[\text { Bill }]_{\mathrm{F}}$ to Sue o $=\lambda \mathrm{w}$.Mary introduced Bill to Sue in $\mathrm{w}$

(100) Mary introduced $[\text { Bill }]_{\mathrm{F}}$ to Sue $\mathrm{ALT}=\{\lambda \mathrm{w}$.Mary introduced $\mathrm{x}$ to Sue $/ \mathrm{x} 0 \mathrm{D}\}$ 
The denotation of only carries an index $\mathrm{C}$ which (through the variable assignment $\mathrm{g}$ ) refers to a contextually determined set of propositions:

(101) only $_{\mathrm{C}}{ }_{\mathrm{o}}^{\mathrm{g}}=\lambda \mathrm{p} \cdot \lambda \mathrm{w} \cdot \mathrm{q}: \mathrm{q} 0 \mathrm{~g}(\mathrm{C}) \& \mathrm{q}(\mathrm{w}) 6 \mathrm{p}=\mathrm{q}$

For a focus sensitive operator such as only, Rooth proposes that its domain of quantification $\mathrm{C}$ is constrained by the focus semantic value. Focus introduces a variable $\mathrm{C}$ which anaphorically constrains the domain of quantification of the focus sensitive operator. Rooth defines the -operator which is adjoined to the variable $\mathrm{C}$ and evaluates the alternatives introduced by the focused constituent. The sentence in (102) can be assumed to have the underlying representation in (103):

(102) Mary only introduced Bill to SUE.

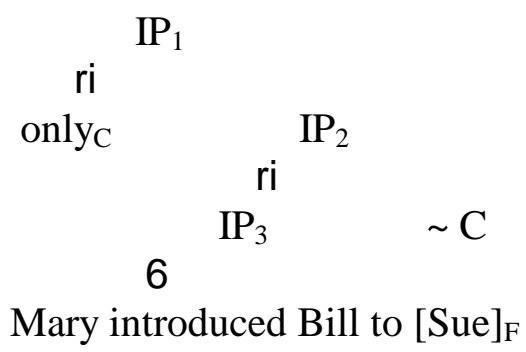

There are two constraints on the variable $\mathrm{C}$ introduced by focus interpretation. The first is that $\varphi \sim \mathrm{C}$ presupposes that $\mathrm{C}$ is a subset of the focus semantic value for $\varphi$ (and contains both the ordinary semantic value of $\varphi$ and an element distinct from the ordinary semantic value of $\varphi$ ). The choice of antecedent for the variable $\mathrm{C}$ is free, but it is guided by the presuppositional constraint introduced by the -operator:

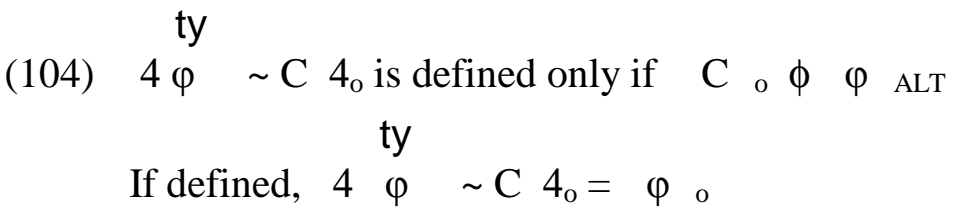


The second constraint is that, in the expression $[\varphi \sim C]$, focus has been interpreted, so the semantic effect of the foci in $\varphi$ has to be neutralized:

(105) $4 \varphi \sim C \quad 4_{\mathrm{ALT}}=\left\{\begin{array}{lll}\varphi & & \\ & \text { ty }\end{array}\right\}$

Rooth $=$ s semantics can also be adopted for predicates such as want. Parallel to only, the predicate want has been defined here as carrying an index $\mathrm{C}$ that refers to a contextually available set of propositions. For convenience, I repeat my proposal for predicates such as want here:

$$
\text { want }_{\mathrm{C}}^{\mathrm{g}}=\lambda \mathrm{p} . \lambda \mathrm{x} . \lambda \mathrm{w} . \quad \mathrm{q}: \mathrm{q} \quad \mathrm{p} \& \mathrm{q} 0 \mathrm{~g}(\mathrm{C}): \mathrm{p}>_{\text {DES x,w }} \mathrm{q}
$$

Just like in the case of only, the index $\mathrm{C}$ of the predicate want should be constrained by the focus semantic value of the embedded clause. The -operator, if placed in the appropriate position in the tree, evaluates the alternatives for the predicate. I illustrate this here with an example from the previous section, with a focused constituent in the embedded clause:

(107) Lisa wants John to teach syntax ON TUESDAYS AND THURSDAYS.

The appropriate tree structure for the sentence in (107) is the one below, where $\sim \mathrm{C}$ is attached at the level of the $\mathrm{CP}$ of the embedded clause. 
(108)

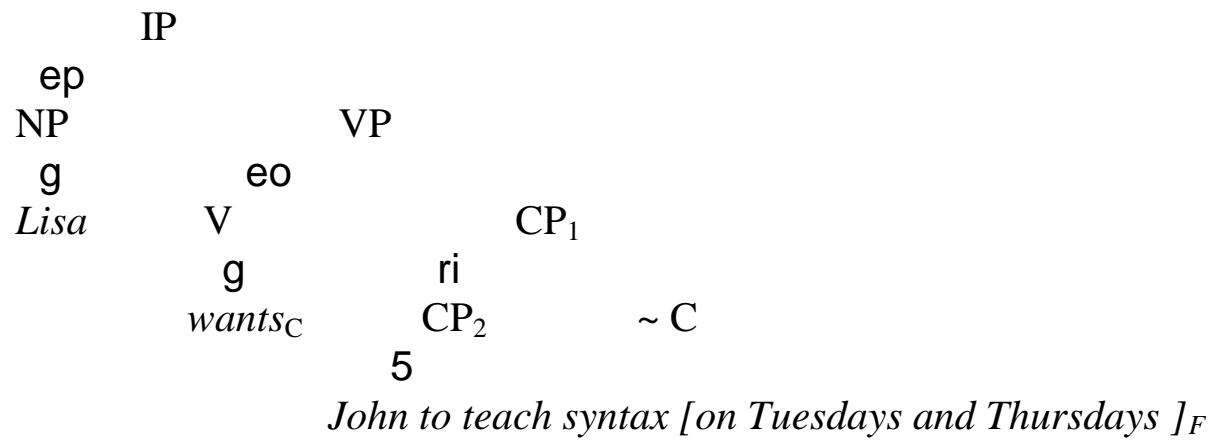

We can thus conclude that Rooth=s proposal for focus sensitive adverbs such as only can straightforwardly be carried over to the predicate want. Notice, however, that we have to ensure that the -operator is adjoined to the CP-level of the embedded clause. Other structures, in which the operator is adjoined to other positions, have to be excluded. The following structure, for example, is uninterpretable because the elements in $\mathrm{C}$ are not of the right type (since $\sim \mathrm{C}$ is adjoined at the $\mathrm{VP}$ level, the elements in $\mathrm{C}$ are of type $\langle\mathrm{e},\langle\mathrm{s}, \mathrm{t}\rangle>)$ :

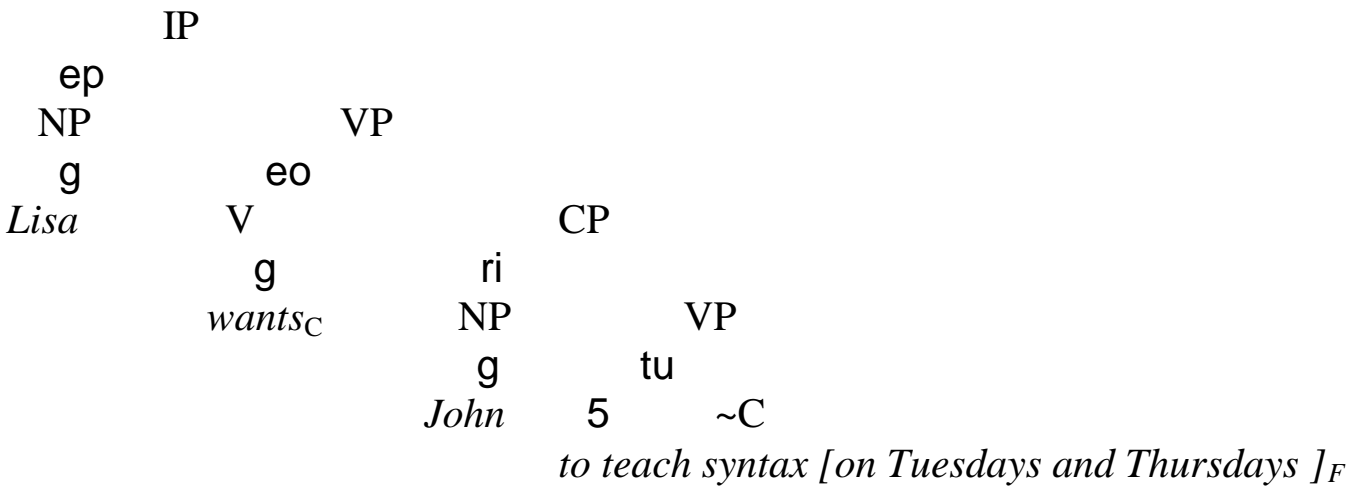

A structure in which the index $\mathrm{C}$ is attached at the IP-level of the higher clause, such as in (110), leads to a nonsensical interpretation: even though the elements in $\mathrm{C}$ are of the right type, $\mathrm{C}$ does not correspond to a set of alternative propositions of the embedded clause. Here, C corresponds to the following set of alternative propositions: \{ $>$ Lisa wants John to teach syntax on Tuesdays and Thursdays $=,>$ Lisa wants John to teach syntax on Mondays, Wednesdays and Fridays $\}$. These are not the appropriate alternatives that the predicate want requires.

$(110)^{*}$

IP

ep 


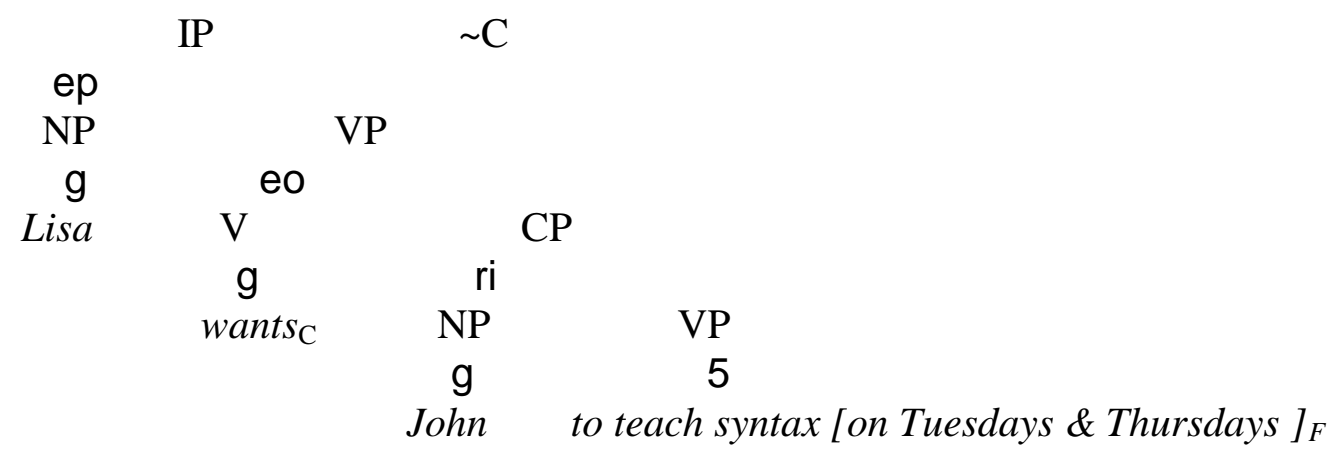

In the following section, I turn to the semantic contribution of the subjunctive mood morpheme. I propose that the role of the subjunctive mood is to ensure that $\mathrm{C}$ contains the appropriate set of alternatives, or in other words, that the evaluation of contextual alternatives happens in the right place of the tree, namely at the level of the embedded clause.

\subsubsection{The subjunctive mood: evaluation of contextual alternatives}

In this section, I return to the Spanish data. I will assume that the subjunctive mood is realized in a projection above IP, presumably in MoodP ${ }^{12}$. I will argue that subjunctive mood is an operator that has the role of the $\sim$-operator, namely to evaluate the alternatives for the matrix predicate. As a consequence, the evaluation of alternatives necessarily happens in MoodP. Subjunctive mood thus ensures that the evaluation of alternatives happens at the right place in the tree. Indicative mood, to the contrary, will be argued to prevent evaluation of alternatives at the level of the embedded clause. I define the $\mathrm{SUBJ}_{\mathrm{C}}$-operator as follows:

\footnotetext{
${ }^{12}$ See Bhatt \& Yoon (1991) for arguments for the existence of the functional projection MoodP. In proposing that MoodP is between CP and IP, I follow Kempchinsky (1998) and references therein.
} 


\section{(111) Definition of SUBJ $\mathbf{J}_{\mathbf{C}}$ :}

ty $\mathrm{g}$

a. $\quad 4 \mathrm{SUBJ}_{\mathrm{C}} \quad \mathrm{IP}_{\mathrm{o}}$ is only defined if $\mathrm{g}(\mathrm{C}) \phi \quad \mathrm{IP}^{\mathrm{g}}{ }_{\mathrm{ALT}} \& \operatorname{Card}(\mathrm{g}(\mathrm{C}))>1$

ty $\mathrm{g}$ when defined $4 \mathrm{SUBJ}_{\mathrm{C}}$ IP $4_{\mathrm{o}}=\mathrm{IP} \mathrm{g}_{\mathrm{o}}$

ty $\mathrm{g}$

b. $\quad 4 \mathrm{SUBJ}_{\mathrm{C}} \quad$ IP $4_{\mathrm{ALT}}=\left\{\right.$ IP $\left.{ }_{\mathrm{o}}^{\mathrm{g}}\right\}$

The semantic contribution of the subjunctive mood can best be illustrated with an example that contains a focused constituent in the embedded clause:

(112) Victoria quiere que Sofía traiga

UNA TORTA DE CHOCOLATE.

Victoria wants that Sofía bring:PRES.SUBJ.3SG a cake of chocolate.

$>$ Victoria wants Sofía to bring A CHOCOLATE CAKE.=

I will assume again that the relevant contextual alternatives are the following: $>$ Sofia bring a chocolate cake $=,>$ Sofia brings ice cream $=$, or $>$ Sofia brings an apple pie $=$. The relevant tree structure corresponding to (112) is given below.

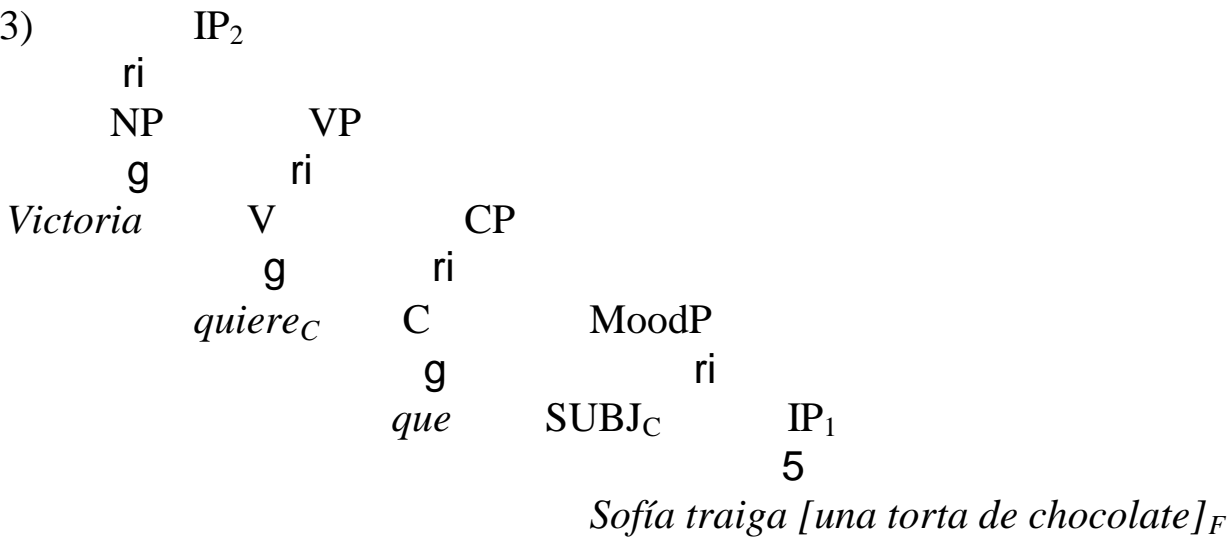

Given the definition of the $\mathrm{SUBJ}_{\mathrm{C}}$-operator, the semantic derivation of (113) is as follows:

$$
\mathrm{IP}_{1} \mathrm{~g}_{\mathrm{o}}=\lambda \mathrm{w} \text {. Sofia brings a chocolate cake in } \mathrm{w} \text {. }
$$


$\mathrm{IP}_{1}{ }_{\mathrm{ALT}}^{\mathrm{g}}=\{\lambda \mathrm{w}$. Sofia brings a chocolate cake in $\mathrm{w}, \lambda \mathrm{w}$. Sofia brings ice cream in $\mathrm{w}, \lambda \mathrm{w}$. Sofia brings an apple pie in $\mathrm{w}\}$

MoodP ${ }_{\mathrm{o}}^{\mathrm{g}}=\mathrm{SUBJ}_{\mathrm{C}} \mathrm{IP}_{1}{ }_{\mathrm{o}}^{\mathrm{g}}$ is only defined if $\mathrm{g}(\mathrm{C}) \phi \mathrm{IP}_{1}{ }_{\mathrm{ALT}}^{\mathrm{g}}=\{\lambda \mathrm{w}$. Sofia brings a chocolate cake in $w, \lambda w$. Sofia brings an apple pie in $w, \lambda w$. Sofia brings ice cream in w\}

when defined

$$
\begin{aligned}
& \text { MoodP }{ }_{0}^{g}=\lambda w \text {. Sofia brings a chocolate cake in } w \\
& \text { MoodP }{ }^{\mathrm{g}}{ }_{\mathrm{ALT}}=\{\lambda \mathrm{w} \text {. Sofia brings a chocolate cake in } \mathrm{w}\} \\
& \mathrm{CP}{ }_{\mathrm{o}}^{\mathrm{g}} \quad=\text { MoodP }{ }_{\mathrm{o}}^{\mathrm{g}}=\lambda \mathrm{w} \text {. Sofia brings a chocolate cake in } \mathrm{w} \\
& \mathrm{CP}{ }_{\mathrm{ALT}}^{\mathrm{g}}=\text { MoodP }{ }_{\mathrm{ALT}}^{\mathrm{g}}=\{\lambda \mathrm{w} \text {. Sofia brings a chocolate cake in } \mathrm{w}\} \\
& \text { want }_{\mathrm{C}}{ }_{\mathrm{o}}^{\mathrm{g}}=\lambda \mathrm{p} \cdot \lambda \mathrm{x} \cdot \lambda \mathrm{w}=. \quad \mathrm{q}: \mathrm{q} \quad \mathrm{p} \& \mathrm{q} 0 \mathrm{~g}(\mathrm{C}): \mathrm{p}>_{\text {DES }}, \mathrm{w}_{=} \mathrm{q} \\
& \mathrm{VP} \mathrm{g}_{\mathrm{o}}^{\mathrm{g}}=\text { want }_{\mathrm{C}} \mathrm{g}_{\mathrm{o}}\left(\mathrm{CP}_{2} \mathrm{~g}_{\mathrm{o}}^{\mathrm{g}}\right)= \\
& =\lambda x \cdot \lambda w=. \quad q: q \quad[\lambda w \text {. Sofia brings a chocolate cake in } w] \& q 0\{\lambda w \text {. Sofia brings a } \\
& \text { chocolate cake in } w, \lambda w \text {. Sofia brings an apple pie in } w, \lambda w \text {. Sofia brings ice cream in } \\
& \mathrm{w}\} \text { : }[\lambda \mathrm{w} \text {. Sofia brings a chocolate cake in } \mathrm{w}]>_{\mathrm{DES} \mathrm{x}, \mathrm{w}=\mathrm{q}} \\
& \mathrm{IP}_{2} \mathrm{~g}_{\mathrm{o}}^{\mathrm{g}}=\mathrm{VP} \mathrm{g}_{\mathrm{o}}^{\mathrm{g}}\left(\mathrm{NP}{ }_{\mathrm{o}}^{\mathrm{g}}\right)= \\
& =\lambda w=. \quad q: q \quad[\lambda w \text {. Sofia brings a chocolate cake in } w] \& q 0\{\lambda w \text {. Sofia brings a }
\end{aligned}
$$

The resulting meaning can be paraphrased as follows: among the relevant alternatives $\{>$ Sofia brings chocolate cake $=,>$ Sofia brings an apple pie $=,>$ Sofia brings ice cream $=\}>$ Sofia brings a chocolate cake $=$ is the most desirable alternative to Victoria.

I thus propose that MoodP is responsible for the evaluation of contextual alternatives for the class of predicates that select the subjunctive mood. These predicates require the subjunctive mood in the embedded clause because they require the presence of a set of contextual alternatives to the embedded proposition. The $\mathrm{SUBJ}_{\mathrm{C}}$-operator evaluates this set of contextual alternatives for the matrix predicate. At the level of the embedded clause, subjunctive mood is thus the morphological realization of Rooth=s -operator. ${ }^{13}$

\footnotetext{
${ }^{13}$ According to this theory of the subjunctive mood, we expect interaction with other possible focus-sensitive
} 
operators in the sentence. For instance, we expect that only should not be able to associate with a chocolate cake in the following example (since we predict that want associates with a chocolate cake):

(i) Victoria only wants Sofia to bring A CHOCOLATE CAKE

However, as pointed out to me by an anonymous reviewer, in English only can associate with the Focus in the embedded sentence. This may potentially be a problem for the theory. Interaction with other focus-sensititive operators will be left for future research. 
Let us now examine what would happen if the embedded clause was in the indicative mood. I will propose that when the $\mathrm{SUBJ}_{\mathrm{C}}$-operator is replaced by the IND-operator, no evaluation of contextual alternatives takes place in MoodP. Rather, the ordinary and alternative semantic values of the IP are simply inherited. In other words, the IND-operator is essentially an identity function.

Is such a definition of the IND-operator sufficient to exclude indicative clauses to appear under predicates such as want? The IND-operator does not evaluate alternatives that may be introduced by a focused constituent in the embedded clause, hence the combination of want with an indicative clause is, in principle, not interpretable (under the assumption that, just like in the case of only, $\mathrm{C}$ has to be constrained by focus and cannot be purely provided by context). However, we still have to exclude the possibility that the -operator could appear in an appropriate position in the structure and do the work that otherwise would be done by the $\mathrm{SUBJ}_{\mathrm{C}}$-operator. In other words, we have to exclude structures of the following kind:

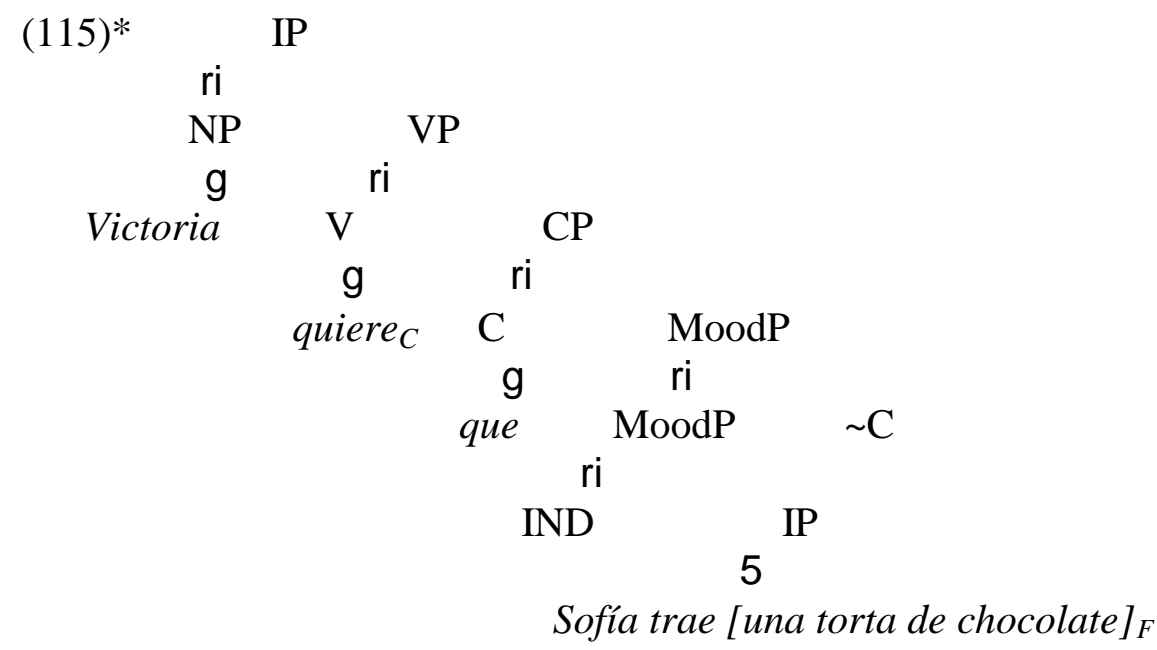

Hence, the IND-operator has to introduce some kind of constraint that prevents evaluation of alternatives at the level of the embedded clause. Notice that the $\sim$-operator should still be able to appear in other positions in the tree. This is so since predicates that select the indicative mood also allow for focused constituents in the embedded clause:

$\begin{array}{ll}\text { Victoria } & \text { sabe que SOFIA trajo una torta de chocolate. } \\ \text { Victoria } & \text { know that Sofía bring:PAST.IND.3SG a cake of chocolate. }\end{array}$

>Victoria knows that SOFIA brought a chocolate cake.= 
In this example, evaluation of contextual alternatives happens at the level of the whole clause. This is seen from the fact that (116) is felicitous in a context that provides alternatives such as $>$ Victoria knows that Marcel brought a chocolate cake $=$, $>$ Victoria knows that Rafael brought a chocolate cake $=$. The corresponding tree structure is given in (117).

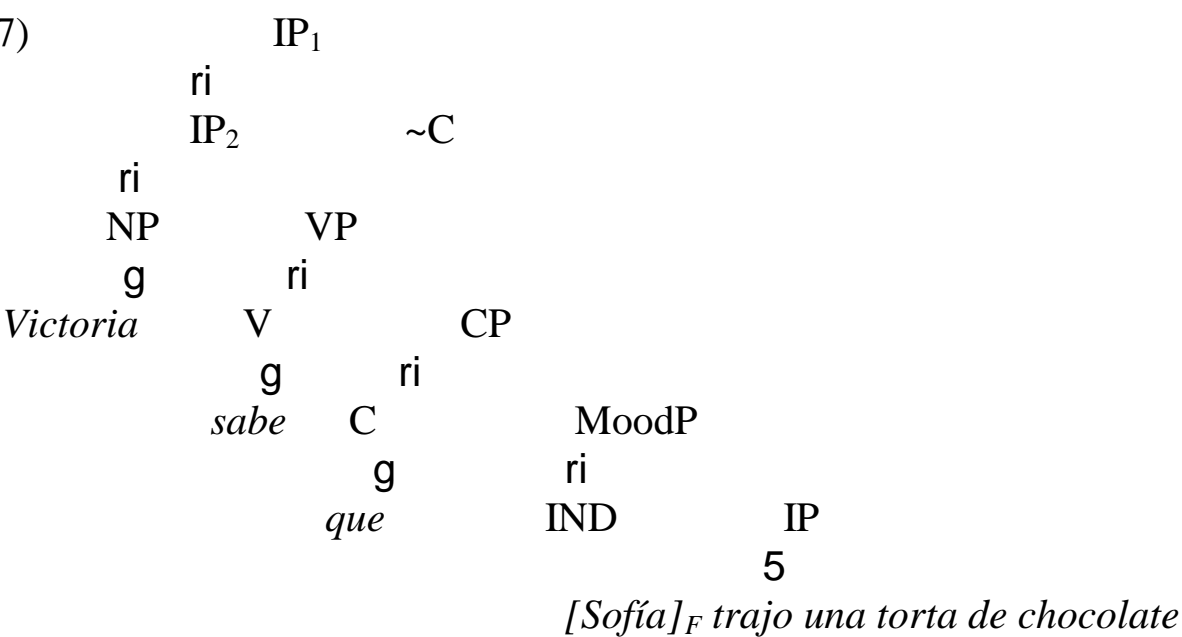

The following example illustrates that evaluation of contextual alternatives may also happen below the level of MoodP, for example in the presence of another focus sensitive operator such as only:

(118) Victoria sabe que solo SOFIA trajo una torta de chocolate. Victoria knows that only Sofía bring:PAST.IND.3SG a cake of chocolate. $>$ Victoria knows that only SOFIA brought a chocolate cake.= 
(119)

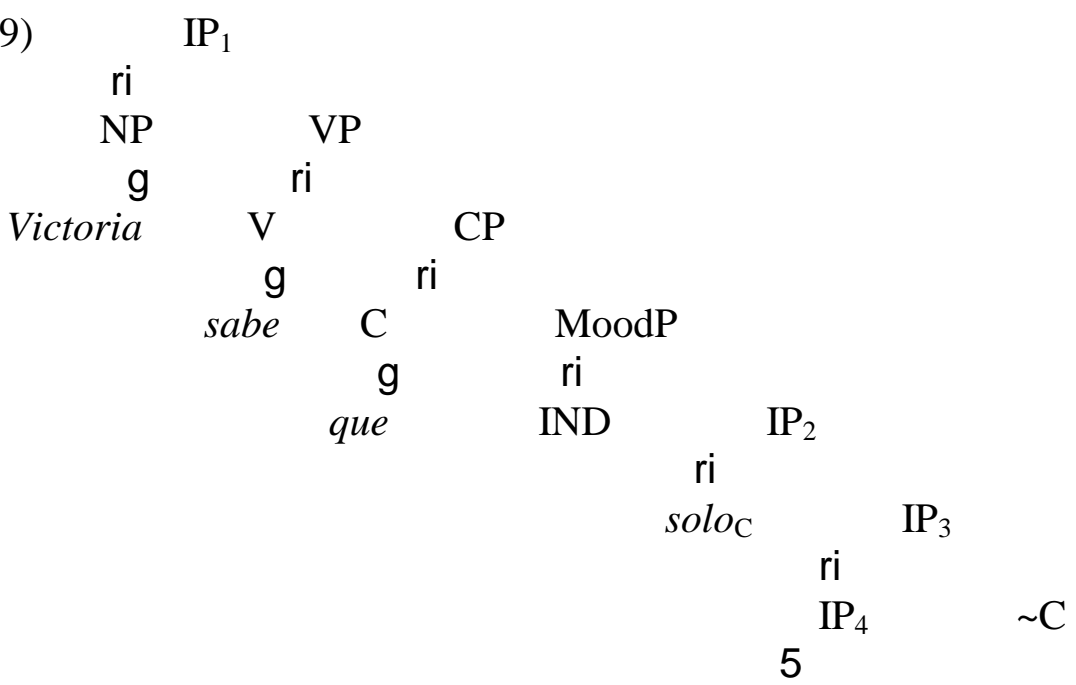

$[\text { Sofía }]_{F}$ trajo una torta de chocolate

We can conclude that for predicates that select the indicative mood the following holds: evaluation of contextual alternatives is possible but not at the level of the embedded MoodP. In order to block evaluation of alternatives at the level of MoodP, I thus propose the following definition of the IND-operator

\section{(120) Definition of $\mathbf{I N D}_{\mathbf{C}}$ :}

$$
\text { ty } \mathrm{g}
$$

a. $\quad 4 \mathrm{IND}_{\mathrm{C}} \quad \mathrm{IP} 4_{\mathrm{o}}$ is only defined if

If there is a $\mathrm{g}(\mathrm{C}) \phi \quad$ IP ${ }^{\mathrm{g}} \mathrm{ALT}$ then $\mathrm{g}(\mathrm{C})=\left\{\mathrm{IP}^{\mathrm{g}}{ }_{\mathrm{o}}^{\mathrm{g}}\right\}$

when defined ty $\mathrm{g}$

$$
4 \mathrm{IND}_{\mathrm{C}} \quad \mathrm{IP} 4_{\mathrm{o}}=\operatorname{IP}{ }_{\mathrm{o}}^{\mathrm{g}}
$$

b. $\quad 4 \mathrm{IND}_{\mathrm{C}}^{\mathrm{g}}$ IP $4_{\mathrm{ALT}}=\operatorname{IP}{ }^{\mathrm{g}}{ }_{\mathrm{ALT}}$

This definition of the $\mathrm{IND}_{\mathrm{C}}$-operator introduces the presupposition that if there is a contextually available set of alternatives included in the alternative semantic value of the IP immediately below MoodP, it only contains one single element, namely the ordinary semantic value of that IP. This constraint prevents a predicate such as want to combine with an indicative clause: a contextually available singleton-set is not sufficient for the interpretation of want. 
The definitions of $\mathrm{SUBJ}_{\mathrm{C}}$ and $\mathrm{IND}_{\mathrm{C}}$ capture the fact that predicates that select the subjunctive mood necessarily require the subjunctive mood in the embedded clause: $\mathrm{SUBJ}_{\mathrm{C}}$ evaluates the contextual alternatives for the matrix predicate, $\mathrm{IND}_{\mathrm{C}}$ prevents evaluation of the contextual alternatives for the matrix predicate. Finally, we need to ensure that the predicates that select the indicative mood also disallow the subjunctive mood in their complement clause. For the moment, nothing would prevent $\mathrm{SUBJ}_{\mathrm{C}}$ to appear under a predicate that selects the indicative mood. To remedy for this, I propose that the following constraint holds for the operator $\mathrm{SUBJ}_{\mathrm{C}}$ :

\section{(121) Constraint on SUBJc:}

$\mathrm{SUBJ}_{\mathrm{C}}$ can only be licensed if it appears in the scope of a focus sensitive operator.

$\mathrm{SUBJ}_{\mathrm{C}}$ is thus different from the $\sim$-operator: $\sim \mathrm{C}$ may appear in a sentence even in the absence of a focus sensitive operator. As it stands, this constraint on $\mathrm{SUBJ}_{\mathrm{C}}$ is a stipulation. However, it captures well the fact that subjunctive mood is essentially a phenomenon in embedded contexts. Furthermore, under certain circumstances, predicates that select the indicative mood do in fact allow for the subjunctive mood in the embedded clause as long as they are embedded under another operator such as negation or the question operator, as illustrated in the examples below ${ }^{14}$.

Lucho no dijo que la comida estuviera lista.

Lucho not said that the food be:PAST.SUBJ.3SG ready.

$>$ Lucho didn=t say that the food was ready.=

Dijo Lucho que la comida lista?

Said Lucho that the food be:PAST.SUBJ.3s ready?

$>$ Did Lucho say that the food was ready?=

\footnotetext{
${ }^{14}$ As pointed out by an anonymous reviewer, the constraint on $\mathrm{SUBJ}_{\mathrm{C}}$ is not precise enough. As it stands, it predicts that $\mathrm{SUBJ}_{\mathrm{C}}$ can be licensed under any focus sensitive operator. Future research will address the question of how the relevant set of focus sensitive operators can be characterized.
} 
$\mathrm{SUBJ}_{\mathrm{C}}$ thus can appear under predicates that select the indicative mood, as long as it is licensed by the presence of negation or the question operator. These are operators that are also known to be focus sensitive.

To conclude, in this section, I have proposed that the semantic contribution of the subjunctive mood is to evaluate the contextual alternatives introduced in the embedded clause. To the contrary, the indicative mood blocks evaluation of contextual alternatives at the level of the embedded clause.

\section{Empirical evidence for a semantics of comparison}

The proposal defended here makes the following important claim: predicates that select the subjunctive mood introduce a gradable property (or ordering relation) with respect to which the contextual alternatives are compared. The ordering relation is contributed by the lexical meaning of each predicate. Under this assumption, we expect predicates that select the subjunctive mood, just like gradable adjectives, to appear in certain types of degree constructions. There are only very few predicates for which this expectation does not hold, namely some of the causative predicates (such as hacer $>$ make $=$ and lograr $>$ achieve $=$ ) and some of the directive predicates (such as ordenar

$>$ order $=)^{15}$. I proposed earlier, in section 5 , that in these cases the comparative meaning component is more deeply embedded within the meaning of the predicate. These predicates are thus not gradable predicates as a whole but rather contain a gradable meaning part. As a consequence, we do not expect them to allow for degree modification on the surface.

In the following, I discuss the distribution of various degree modifiers such as mucho $(>$ much $=)$, bastante $(>$ quite $=)$, demasiado $(>$ too much $=)$, enormemente $(>$ enormously $=)$, and the comparative construction with predicates that select the subjunctive/indicative mood. The distribution of these degree modifiers provides further evidence for the proposal defended here.

\subsection{Gradability in the adjectival versus verbal domain}

Gradable predicates such as tall express properties that are ordering inducing: we can compare individuals according to whether they have the property of being tall to a greater or lesser extent. The

\footnotetext{
${ }^{15}$ See the appendix for more examples.
} 
crucial difference between gradable and non gradable predicates is that the domains of gradable predicates can be partially ordered according to some gradient property, whereas the domains of nongradable predicates cannot.

For adjectives, modifiers such as $>$ very $=$ are an indicator of their gradable/non gradable nature: while gradable adjectives can combine with $>$ very $=$, non gradable ones cannot. The sentence in (124) expresses that the victim is tall to a high degree, while the sentence in (125) cannot express that the victim is dead to a high degree:

(124) The victim is very tall.

(125) *The victim is very dead.

Another good test for the gradable/non gradable nature of an adjective is the comparative construction. Only gradable expressions can appear in comparative constructions:

(126) The victim is taller than his neighbor.

(127) *The victim is more dead than his neighbor.

When we turn to the verbal domain, the tests for gradability are less straightforward. Bolinger (1972) suggests that we can distinguish degree verbs from non degree verbs by their acceptance of lexical intensifiers such as quite, rather, so, etc. Thus, in the example (128), the acceptability of the modifier quite indicates that the predicate exasperate is a degree verb. The modifier quite expresses that there is a quite high degree of exasperation.

(128) He quite exasperates me. (Bolinger 1972)

However, Bolinger points out that such modifiers do not always signal degree modification. In fact, a number of these degree modifiers are ambiguous and do not necessarily modify the degree of the intensity of the property denoted by the predicate. For example, a modifier such as much as in (129) can also be used to modify the extensibility of a predicate. Here, the modifier indicates that the quantity of talking was high, not the intensity of talking. 
(129) He talks too much. (Bolinger 1972)

Doetjes (1997) points out that there is one class of modifiers that is not ambiguous in this way, but has a much more restricted distribution: high degree adverbs such as >enormously=exclusively modify the degree of the intensity of a property. The examples below illustrate that enormously can be used to express a very high degree of appreciation, but not to express a very high quantity of moviegoing.

(130) John appreciated the movie enormously

(131) *Anne goes enormously to the movies.

(Doetjes 1997, p.122)

The modifier >enormously= thus seems to be the best test for distinguishing gradable from nongradable predicates. I now turn to the distribution of degree modifiers with the predicates under discussion.

\subsection{Degree modification for predicates that select the subjunctive/indicative mood}

In this section, I show that predicates that select the subjunctive mood differ from predicates that select the indicative mood in what type of degree modification they allow.

A wide range of the predicates that select the subjunctive mood in Spanish allow for modification with enormemente (>enormously=). This holds for all desire predicates, most emotive factive predicates, all predicates of doubt, all predicates of probability and possibility and some of the directive and causative predicates, as illustrated in the examples below ${ }^{16}$.

(132) Marcela desea enormemente que Rafael venga.

Marcela desires enormously that Rafael come:SUBJ.PRES.3SG.

> Marcela enormously wants Rafael to come.=

\footnotetext{
${ }^{16}$ See the appendix for more examples.
} 
(133) Sofía se alegra enormemente de que la vengan a visitar.

Sofía SE glad enormously of that PRO her come:PRES.SUBJ.3PL to visit.

$>$ Sofía is enormously glad that they will visit her.=

(134) Te sugiero enormemente que no salgas.

PRO you suggest enormously that PRO not leave:PRES.SUBJ.2SG.

$>$ I suggest enormously that you don $=\mathrm{t}$ leave $=$

However, among the emotive factive predicates, there are some predicates that cannot combine with high degree modifiers: certain predicates that express high extremes of scales such as es estupendo ( $>$ it is great=) and es extraordinario ( $>$ it is extraordinary=), as well as predicates that express a lower bound of a scale such as aceptar ( $>$ accept=), and es suficiente ( $>$ it is sufficient=). For predicates that express such extremes of scales it is not unexpected that they disallow high degree adverbs. High degree adverbs simply contribute redundant information in this case. Notice that all of these predicates allow for other degree modifiers such as muy (>very=). Furthermore, as we will see below, they can also appear in comparative constructions.

There are also a few other emotive factive predicates that do not allow for high degree modifiers, such as es lógico ( $>\mathrm{it}$ is logic=), es natural ( $>\mathrm{it}$ is natural=), es normal ( $>\mathrm{it}$ is normal=), es mejor ( $>$ it is better $=$ ) and es peor ( $>$ it is worse=). For some reason, these predicates resist high degree modification. They do however allow for degree modifiers such as muy (>very=) and mucho ( $>$ much $=)$. Since all the above mentioned examples are adjectives, I will assume that the possibility of the modifier muy (>very=) is sufficient a test to show that they denote gradable properties. Again, all of these predicates can also appear in comparative constructions.

To the contrary, none of the predicate classes that select the indicative mood allow for modification with high degree adverbs such as enormemente (>enormously=) (with the exception of the class of predicates of certainty). The incompatibility with high degree adverbs is illustrated in the examples below with an epistemic predicate $\operatorname{saber}(>\mathrm{know}=)$, and a predicate of communication decir $(>$ say $=)$. 
(135)

*Sofia sabe enormemente que no puede venir.

Sofia knows enormously that PRO not can:PRES.IND.3SG come.

$*=$ Sofia knows enormously that she cannot come. $=$

(136) *Alberto dijo enormemente que tenía hambre.

Alberto said enormously that PRO have:PAST.IND.3SG

hungry.

* >Alberto said enormously that he was hungry.=

As expected under the proposal, all predicates that select the subjunctive mood (with the exception of certain directive and causative predicates) allow for modification with a whole range of other degree modifiers such as mucho $(>$ much $=)$, bastante $(>$ quite $=)$, tanto $(>$ so much $=)$, demasiado (>too much=):

(137) Marcela teme mucho que Rafael venga.

Marcela fears much that Rafael come:SUBJ.PRES.3SG.

$>$ Marcela very much fears that Rafael will come. $=$

(138) Sofía se alegra tanto de que la vengan a visitar.

Sofía SE glad so of that PRO her come:PRES.SUBJ.3PL to visit.

>Sofía is so glad that they will come to visit her.=

To the contrary, with predicates that select the indicative mood these modifiers are inacceptable (when they express modification of the intensity of the property):

*Rafael sabe mucho que no tiene razón.

Rafael knows much that PRO not have:IND.PRES.3SG right.

$>$ Rafael much knows that he is not right.=

(140) *Rafael promete mucho que podrá venir.

Rafael promises much that PRO can:FUT.IND.3SG come.

$>*$ Rafael promises much that he will be able to come.= 
For predicates that select the indicative mood, when modification with such degree modifiers is possible, they can only express modification of the extensibility of the predicate or repetition. Thus, in the example below, with the predicate of communication decir

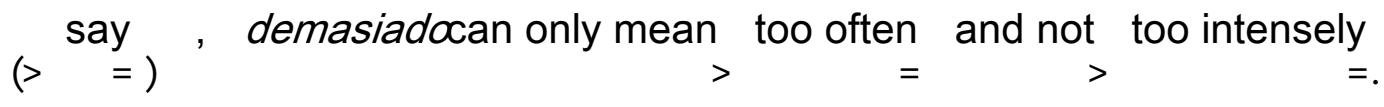

(141) Alberto dijo demasiado que

Alberto said too-much that PRO

$$
\begin{aligned}
& \text { tenía } \\
& \text { have:PAST -IND } 3 \text { SSG } \\
& \text { hunger }
\end{aligned}
$$

\begin{abstract}
Alberto said too often that he was hungry.
\end{abstract}
Importantly, for those predicates that can select both the indicative and the subjunctive mood, degree modification is only possible when the subjunctive mood is selected. This is illustrated here with the predicate sentir:

$$
\text { Siento enormemente que te hayan hecho daño. }
$$

PRO sorry enormously that PRO you have:PAST.SUBJ.3PL done pain.

$>$ I am enormously sorry about the fact that they have hurt you.=

* Siento enormemente que va a haber un problema.

PRO sense enormously that PROgo:FUT.IND.3SG to there-be a problem.

* $>$ I sense enormously that there is going to be a problem.=

The predicate esperar has also been claimed to allow for mood alternation (cf. Ridruejo 1999) ${ }^{17}$. When this predicate selects the subjunctive mood it has the meaning of the factive emotive predicate

\footnotetext{
${ }^{17}$ However, the indicative mood is only possible when the embedded clause is about a future event (as pointed out in Ridruejo(1999):

(Error! Main Document Only.) Espero que venga /vendrá mi hermano PRO hope that come:PRES.SUBJ.3SG/come:: FUT.IND.3SG my brother

(Error! Main Document Only.) Espero que mi hermano viniera/*ha venido ayer PRO hope that my brother come:PAST.SUBJ.3SG/*PAST.IND.3SG
} 
$>$ to hope $=$, whereas when it selects the indicative mood it has the meaning $>$ to anticipate $=/=$ to expect $=$. Crucially, modification with $>$ enormemente $=$ is possible only when the predicate selects the subjunctive mood:

Espero enormemente que venga mi hermano PRO hope enormously that come:PRES.SUBJ.3SG my brother $>$ I enormously hope that my brother will come=
$(145) *$
Espero enormemente que vendrá
mi hermano.
PRO hope enormously that come:FUT.IND.3SG my brother
*>I enormously anticipate that my brother will come.=

Among the predicates that select the indicative mood, an exception is formed by the class of predicates of certainty such as estar seguro (>be certain=). For these predicates, degree modification is in fact possible. We will see, however, that the semantics of these predicates does not involve comparison of contextual alternatives.

Imagine again a context in which there are the following three possibilities: Sofia may bring a chocolate cake, she may bring an apple pie or she may bring ice cream. In this scenario, the interpretation of a sentence containing the predicate be certain does not involve ranking the possible alternatives on a scale of certainty. For example, the sentence in (146) does not imply (147). Rather it implies (148):

(146) Victoria is certain that Sofia will bring chocolate cake.

(147) Victoria is less certain that Sofia will bring ice cream.

(148) Victoria is certain that Sofia will not bring ice cream.

We have seen previously that for predicates such as want the contextual alternatives are ranked on a scale of desirability. Thus, if Victoria wants Sofia to bring chocolate cake, this implies that the other alternatives are ranked lower on the scale of Victorias desirability. As we have seen here, this is not the case for a predicate such as be certain. If Victoria is certain that Sofia will bring a chocolate cake, this does not imply that she is less certain about the other alternatives. ${ }^{18}$

\footnotetext{
${ }^{18}$ The predicate creer $>$ believe= also allows for modification with enormemente and mucho (the only predicate in
} 
the class of epistemic predicates).Parallel to predicates of certainty, if Victoria believes that Sofia will bring a chocolate cake, this does not imply that she believes less in the other alternatives. Rather it implies that Victoria believes that Sofia will NOT bring ice cream. 
Finally, there is one further type of empirical evidence for gradability, namely the kind of comparative construction illustrated in the example (149).

(149) It is more likely that Sofia will bring a chocolate cake than that she will bring an apple pie.

Notice that, in this example, overt comparison is established between two of the possible alternatives, namely $>$ that Sofia will bring a chocolate cake $=$ and $>$ that Sofia will bring an apple pie $=$. This kind of comparative construction is thus a very straightforward test for the proposal developed here. As expected, apart from the class of directives and causatives, all predicate classes that select the subjunctive mood can appear in such comparative constructions. To the contrary, predicates that select the indicative mood cannot appear in comparative constructions of this kind. This is illustrated in the examples below.

(150) Sofia teme más que pueda perder su trabajo que no que tenga que trabajar demasiado. $>$ Sofia fears more that she could loose her job than that she may have to work too much.=

(151) Es más probable que Rafael venga a la fiesta que no que Lucia venga. $>$ It is more likely that Rafael will come to the party than that Lucia will come.=

(152) *Sofia sabe más que Lucia vendrá a la fiesta que no que Rafael vendrá. * $>$ Sofia knows more that Lucia will come to the party than that Rafael will come.=

(153) * Sofia comprendio más que tenía que trabajar demasiado que no que podía cambiar de trabajo. $>$ *Sofia understood more that she had to work too much than that she could change her job.=

To conclude, in this section I have provided empirical evidence for the claim that predicates that select the subjunctive mood are gradable predicates. These predicates can combine with degree modifiers and can appear in a certain type of comparative construction, contrary to the predicates that select the indicative mood. 


\subsection{Refining the proposal: predicates that select the subjunctive mood have an extra degree argument}

In this section, I will refine the proposal in order to accommodate the empirical facts presented above. In doing so, I will follow recent semantic literature that has adopted a scalar analysis ${ }^{19}$ for the semantics of gradable adjectives. In the scalar approach, gradable adjectives are analyzed as relations between individuals and degrees. In the literature, there are different variants as to what exactly the denotation of a gradable adjective should be. I will assume here that a predicate such as tall is a function of type $\langle\mathrm{d},\langle\mathrm{e},\langle\mathrm{s}, \mathrm{t}\rangle>>$ :

$$
\text { tall }=\lambda \mathrm{d}_{\mathrm{d}} \cdot \lambda \mathrm{x}_{\mathrm{e}} \cdot \lambda \mathrm{w}_{\mathrm{s}} . \mathrm{x} \text { is tall to a degree } \mathrm{d} \text { in } \mathrm{w} \text {. }
$$

Similarly, I will assume that the predicate want is a function of type $\langle\mathrm{d},\langle\langle\mathrm{s}, \mathrm{t}\rangle,\langle\mathrm{e},\langle\mathrm{s}, \mathrm{t}\rangle\rangle\rangle$ :

$$
\text { want }=\lambda \mathrm{d} \cdot \lambda \mathrm{p} . \lambda \mathrm{x} \cdot \lambda \mathrm{w} . \mathrm{x} \text { wants } \mathrm{p} \text { to a degree } \mathrm{d} \text { in } \mathrm{w} .
$$

The degree morphology then applies to this function and imposes some requirement on the degree. This requirement is different for each type of degree construction (absolute, comparative, superlative and equative constructions). For each different construction in which the predicate may appear, this degree morpheme introduces a different ordering relation. In absolute constructions, the ordering relation is contributed by an abstract l-morpheme. In comparative, superlative and equative constructions the overt morphemes more, less, most or as take the place of this abstract 1-morpheme.

I will thus propose that, for predicates such as want, the comparison relation is introduced by an abstract 1-morpheme. Notice that, in such an analysis, the l-morpheme has the meaning of a superlative morpheme, rather than an absolute morpheme (as is the case for adjectives). I will not make any commitments as to what exactly the syntax of the verbal projection should be (see, for example, Kennedy 1999 who proposes that adjectives have an extended projection DegP that hosts

\footnotetext{
${ }^{19}$ See for example Bartsch \& Venneman (1973), Bierwisch (1989), Cresswell (1976), Heim (1985, 2000), Kennedy (1999,2001), Kennedy \& McNally (2005), Klein (1991), von Stechow (1984a,b). See Kennedy (1999) for an overview of scalar analyses of gradable adjectives.
} 
their degree morphology). For the sake of simplicity, I will assume that the degree morpheme is attached at the $\mathrm{V}=-$ level, in the same position in which we find other verbal modifiers. For the predicate want, this abstract $\mathbf{l}$-morpheme carries the variable $\mathrm{C}$ (which refers to the set of contextual alternatives to $\mathrm{p})$ :

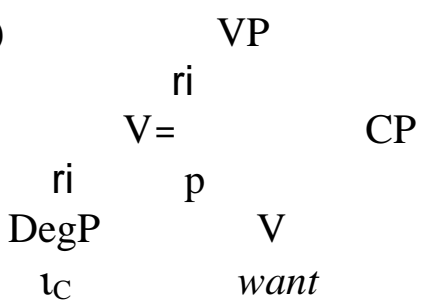

The denotation of the whole VP should be the following:

$$
\begin{aligned}
& \text { VP }{ }^{g}=\lambda x . \lambda w . \quad q: q \quad \text { p \& q } 0 \mathrm{~g}(C): \\
& \max (\lambda d . x \text { wants } \mathrm{p} \text { to a degree } d \text { in } w)>\max (\lambda d=. x \text { wants q to a degree } d=\text { in } w) \\
& \text { where } \max (S)=\mathrm{xx}: x 0 S \& \quad y[y 0 S \Psi y \quad x]
\end{aligned}
$$

We obtain this meaning from the two following parts:

$$
\begin{aligned}
& \text { want }^{\mathrm{g}} \quad=\lambda \mathrm{d} \cdot \lambda \mathrm{p} . \lambda \mathrm{x} \cdot \lambda \mathrm{w} . \mathrm{x} \text { wants } \mathrm{p} \text { to a degree } \mathrm{d} \text { in } \mathrm{w} \text {. }
\end{aligned}
$$

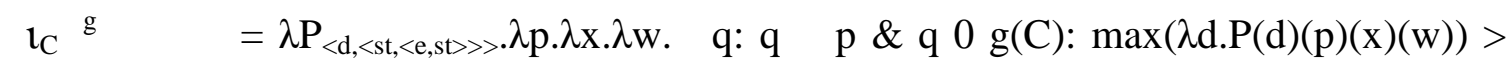

$$
\begin{aligned}
& \max (\lambda d=. P(d=)(q=)(x)(w))
\end{aligned}
$$

In fact, some clarification is in order to explain how this proposal for the meaning of the predicate want is related to the definition developed previously in section 4. Before, the comparison relation $>_{\mathrm{DES} \alpha, \mathrm{w}}$ was used to compare propositions, here $>$ is used to compare degrees. Based on the definition of the relation $>_{\mathrm{DES} \alpha, \mathrm{w}}$, we can express the meaning of a degree by defining an equivalence relation (following Cresswell1976):

(160) Definition of an Equivalence Relation .:

$$
\mathrm{p} . \mathrm{q} \quad \text { iff } \quad \mathrm{z} \text { : }\left(\mathrm{p}>_{\mathrm{DES} \alpha, w} \mathrm{z} \text { iff } \mathrm{q}>_{\mathrm{DES} \alpha, w} \mathrm{z}\right) \&\left(\mathrm{z}>_{\mathrm{DES} \alpha, w} \mathrm{p} \text { iff } \mathrm{z}>_{\mathrm{DES} \alpha, w} \mathrm{q}\right)
$$


We can now define a relation $>$ DESa,w of all $>_{\mathrm{DES} \alpha, \mathrm{w}}$-equivalence classes ( ) stands for field of a relation: Athe set of all things that are related in one direction or another to something elsee Cresswell1976, p. 266, and $p$ stands for the degree to which $\mathrm{p}$ is desirable):

(161) $\mathrm{p} 0)\left(>_{\mathrm{DES} \alpha, \mathrm{w}}\right)$ iff $\left.\mathrm{p} 0\right)\left(>_{\mathrm{DES} \alpha, \mathrm{w}}\right): \underline{\mathrm{p}}=\{\mathrm{z}: \mathrm{z} \cdot \mathrm{p}\}$

(162) $\mathrm{p} \quad>\mathrm{DES} \alpha, \mathrm{w} \quad$ iff $\quad \mathrm{p}>_{\mathrm{DES} \alpha, w} \mathrm{q}$

The meaning of the predicate want should thus be as follows.

$$
\begin{gathered}
\text { want }^{\mathrm{g}}=\lambda \mathrm{d} \cdot \lambda \mathrm{p} \cdot \lambda \mathrm{x} \cdot \lambda \mathrm{w} . \mathrm{x} \text { wants } \mathrm{p} \text { to a degree } \mathrm{d} \text { in } \mathrm{w} . \\
\text { where } \mathrm{d} 0)\left({ }_{\text {DES }, \mathrm{w}}\right)
\end{gathered}
$$

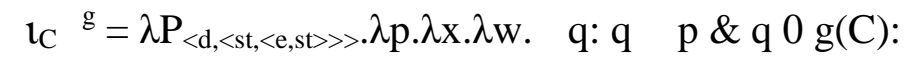

$$
\begin{aligned}
& \max (\lambda d \cdot P(d)(p)(x)(w)) \quad>\text { DESx,w } \max (\lambda d=. P(d=)(q=)(x)(w)) \\
& \text { where d } 0)\left({ }_{>D E S x, w}\right) \\
& \text { and } \max (S)=1 x: x \text { 0 S \& } \quad y[y 0 S \Psi y \quad x]
\end{aligned}
$$

$$
\begin{aligned}
& \mathrm{VP}^{\mathrm{g}}=\lambda \mathrm{x} . \lambda \mathrm{w} . \quad \mathrm{q}: \mathrm{q} \quad \mathrm{p} \& \mathrm{q} 0 \mathrm{~g}(\mathrm{C}): \max (\lambda \mathrm{d} \text {. } \mathrm{x} \text { wants } \mathrm{p} \text { to a degree } \mathrm{d} \text { in } \mathrm{w}) \\
& >\text { DESx,w } \max (\lambda d=\text {. } x \text { wants } q \text { to a degree } d=\text { in } w) \\
& \text { where d } 0)(\text { DESX,w }) \\
& \text { and } \max (S)=1 x: x 0 S \& \quad y[y 0 S \Psi y \quad x]
\end{aligned}
$$

The definition in (165) thus replaces the previous definition of the meaning of the predicate want from section 4 . Notice that this proposal amounts to analyzing the comparative as a phrasal comparative, as in Heim(1985).

To conclude, in this section, I have refined my proposal for the semantics of the predicates that select the subjunctive mood. Following the recent literature on the semantics of gradable predicates, I have proposed that these predicates have an additional degree argument. Furthermore, the meaning of the predicate is decomposed into two parts. The predicate introduces the dimension of comparison (for the predicate want the dimension is desirability), and the l-morpheme introduces the comparative 
meaning component, as well as the variable $\mathrm{C}$. When these predicates are modified by some degree modifier such as mucho $(>$ much=) or enormemente (>enormously=), or appear in a comparative construction, the 1-morpheme in DegP is replaced by the corresponding degree morpheme.

\section{Conclusion}

In this paper, I have argued for a new semantics of the predicates that select the subjunctive mood in Spanish, a semantics based on the comparison of contextually relevant alternatives.

I have proposed the following generalization for the subjunctive mood in Spanish complement clauses: a proposition $\mathrm{p}$ that is the complement of the matrix predicate requires the subjunctive mood iff the matrix predicate introduces an ordering relation (or scale) and compares $p$ to its contextually available alternatives. This generalization captures the fact that whether these alternatives are possible or counterfactual alternatives is irrelevant for the distribution of the subjunctive mood.

Furthermore, I have addressed the following important question: what role does the subjunctive mood morpheme play in the semantic composition of the sentence? The literature on the semantics of mood rarely addresses this question. The main focus of the great majority of these studies has rather been to provide a characterization of the contexts in which the subjunctive mood appears. The investigation of what the subjunctive mood contributes to the meaning composition provides a first step towards a better understanding of why subjunctive verb forms require special semantic licensing conditions and why they are obligatory in certain contexts.

In the analysis presented here, the predicates that select the subjunctive mood are treated as focus sensitive operators, and the subjunctive mood morpheme is given the role of evaluating the alternatives for the focus sensitive operator. Subjunctive mood is then licensed by the presence of a focus sensitive operator. This analysis has the advantage that it may be extended to other contexts in which the subjunctive mood appears. It is well known that the subjunctive mood in complement clauses may also be triggered under negation and in questions. As has been widely assumed in the literature (cf. for example Büring 1999, Borgonovo 2003, Erteshik-Shir 1997, Jakobs 1983,1991, Partee 1991,1993) negation can be analyzed as a focus sensitive operator. Parallel to what I have proposed here, in the context of negation, the subjunctive mood morpheme can then have the same role of evaluating the alternatives for the negation operator (see Villalta 2006). Similarly, Beck (to appear) proposes that the question operator $\mathrm{Q}$ accesses the alternative semantic value of the 
proposition to turn the sentence into a question denotation, namely the alternative semantic value of the sentence. Assuming that this question operator is a focus sensitive operator, the subjunctive mood morpheme could, in the context of a question, have the same role as in the other contexts: namely to evaluate the contextual alternatives for the focus sensitive operator.

Finally, I have shown that two important properties of the predicates that select the subjunctive mood follow directly from the proposal developed here. These predicates are focus sensitive and they are gradable. The focus sensitivity of these predicates follows directly from the fact that they are analyzed analogous to focus sensitive operators such as only. Their gradability follows from the fact that they are analyzed as introducing an ordering relation or scale. After presenting the empirical evidence for a comparative semantics, I have revised the analysis accordingly: in the final proposal, predicates that select the subjunctive mood carry an extra degree argument. This final proposal points to a parallelism between the semantics of predicates that select the subjunctive mood and what has been proposed for the semantics of gradable adjectives in the literature. 


\section{References}

Bartsch, R. and T. Venneman (1973). Semantic Structures: A Study in the Relation between Syntax and Semantics. Frankfurt: Athenäum Verlag.

Beck, S. (2006). >Intervention Effects follow from Focus Interpretation=.Natural Language Semantics 14.1-56.

Beck, S. (to appear). > The Grammar of Focus Interpretation=. Proceedings of the Berlin Symposium $>$ Interfaces + Recursion $=$ Language $=$.

Bhatt, R. \& J. Yoon (1991). > On the composition of COMP and parameters of V2'. In D. Bates (ed.) Proceedings of the West Coast Conference on Formal Linguistics 10. 41-52.

Bierwisch, M. (1989). > The Semantics of Gradation=. In M. Bierwisch and E. Lang (eds.) Dimensional Adjectives. Berlin: Springer-Verlag. 71-261.

Boër, S. (1979). > Meaning and Contrastive Stress=. The Philosophical Review 2. 263-298.

Bolinger, D. (1968). >Postposed Main Phrases: An English rule for the Romance subjunctive=. Canadian Journal of Linguistics 10. 125-197.

Bolinger, D. (1972). Degree Words. De Hague: Mouton.

Borgonovo, C.(2003). > Mood and Focus=. In J. Quer et al. (eds.). Romance Languages and Linguistic Theory 2001. Amsterdam/Philadelphia: John Benjamins. 17-30.

Büring, D. (1999). > Drinking, Accents, And Negation=. In E. Benedicto \& al. (eds.) Proceedings of the Focus Workshop. University of Massachusetts Working Papers 21. Amherst, MA: GLSApublications. 37-50.

Cresswell, M. J. (1976). > The semantics of degree=. In B.H. Partee (ed.) Montague Grammar. New York: Academic Press. 261-292.

Doetjes, J. (1997). Quantifiers and Selection: On the Distribution of Quantifying Expressions in French, Dutch and English. PhD dissertation. Leiden University.

Dretske, F. (1972). >Contrastive Statements=. Philosophical Review 81. 411-437.

Dretske, F. (1975). > The Content of Knowledge=. In B. Freed et al. (eds.) Forms of Representation. Amsterdam: North Holland Publishing Company.77-93.

\footnotetext{
Egea, E. 1979 . Los adverbios terminados en mente en el espa ol contempor neo. Bogot :

á Publicaciones del Instituto Caro y Cuervo XLIX.
} 
Erteschik-Shir, N. (1997). The dynamics offocus structure. Cambridge: Cambridge University Press. Farkas, D. (1985). Intensional Descriptions and the Romance Subjunctive Mood. New York: Garland. Farkas, D. (1992). > On the Semantics of Subjunctive Complements=. In P. Hirschbuehler \& K. Koerner (eds.) Romance Languages and Modern Linguistic Theory. Amsterdam/Philadelphia: John Benjamins. 69-103.

Farkas, D. (2003). >Assertion, Belief and Mood Choice=. Ms. University of Santa Cruz.

von Fintel, K.(1994). Restrictions on Quantifier Domains. PhD Dissertation. University of Massachusetts at Amherst.

von Fintel, K. (1999). > NPI-Licensing, Strawson-Entailment, and Context-Dependency=. Journal of Semantics 16. 97-148.

von Fintel, K. \& S. Iatridou (2007). AAnatomy of Modal Construction@, Linguistic Inquiry 38.445483.

Giannakidou, A. (1997). The Landscape of Polarity Items. PhD dissertation. University of Groningen, the Netherlands.

Giannakidou, A. (1998). Polarity Sensitivity as (Non) Veridical Dependency. Amsterdam/ Philadelphia: John Benjamins.

Giannakidou, A. (1999). >Affective Dependencies=. Linguistics and Philosophy 22. 367-421.

Giorgi A. \& F. Pianesi (1997). Tense and Aspect, From Semantics to Morphosyntax. Oxford: Oxford University Press.

Givón, T. (1994). >Irrealis and the Subjunctive=. Studies in Language 18-2. 265-337.

Heim, I. (1985). Notes on Comparatives and Related Matters. Ms, University of Texas, Austin.

Heim, I. (1992). >Presupposition Projection and the Semantics of Attitude Verbs=. Journal of Semantics 9. 183-221.

Heim, I. (2000). > Degree Operators and Scope=. In B. Jackson and T. Matthews (eds.) Semantics and Linguistic Theory 10. 40-64.

Hintikka, J. (1962). Knowledge and Belief. Ithaca: Cornell University Press.

Hintikka, J. (1969). >Semantics for propositional attitudes=. In J.W. Davis et al. (eds.) Philosophical Logic. Dordrecht: Reidel. 21-45.

Hooper, J. (1975). >On Assertive Predicates=. In J. Kimball (ed.). Syntax and Semantics 4. New York/London: Academic Press. 91-124. 
Hooper, J. \& Thompson S.A. (1973). >On the applicability of root transformations=. Linguistic Inquiry 4. 465-497.

Jakobs, J. (1983). Fokus und Skalen. Tübingen: Max Niemeyer Verlag.

Jakobs,J. (1991). >Negation=. In Arnim von Stechow \& Dieter Wunderlich (eds.) Semantik/Semantics: An International Handbook of Contemporary Research. Berlin: de Gruyter.

Kadmon N. \& F. Landman (1993). >Any=. Linguistics and Philosophy 16. 353-422.

Kamp, H. (1975). > Two Theories of Adjectives=. In E. Keenan (ed.) Formal Semantics of Natural Language. Cambridge: Cambridge University Press. 123-155.

Katz, E. G. (1991). > The Downward Entailingness of Conditionals and Adversatives.= In FLSM II: Papers from the 2nd Annual Meeting of the Formal Linguistics Society of Midamerica. Bloomington: IULC Publications. 217-243.

Kempchinsky, P. (1998). >Mood Phrase, Case Checking and Obviation=. In T. Schwegler \& M. Uribe-Etxebarría (eds). Selected Proceedings of the 27th Linguistic Symposium on Romance Languages. Amsterdam: John Benjamins. 143-154.

Kennedy, C. (1999). Projecting the Adjective. The Syntax and Semantics of Gradability and Comparison. New York: Garland.

Kennedy, C. (2001). >Polar Opposition and the Ontology of $>$ Degrees==Linguistics and Philosophy 24. 33-70.

Kennedy, C. and L. McNally (2005). >Scale Structure and the Semantic Typology of Gradable Predicates=. Language 81(2).1-37.

Kiefer, F. (1987). >On Defining Modality=. Folia Linguistica 21. 67-94.

Klein, E. (1980). >A Semantics for Positive and Comparative Adjectives=. Linguistics and Philosophy 4.1-45.

Klein, E. (1991). >Comparatives=. In Arnim von Stechow \& Dieter Wunderlich (eds.) Semantik/Semantics, An International Handbook of Contemporary Research. Berlin: de Gruyter. 673-691.

Krasikova, S. (2007). > Universal modals in comparative clauses=. In Grønn, Atle (ed.). Proceedings of SUB12, Oslo.

Kratzer, A. (1977). $>$ What $>$ must $=$ and $>$ can $=$ must and can mean=. Linguistics and Philosophy 1. 337-355. 
Kratzer, A. (1981). > The Notional Category of Modality=. In H.-J. Eikmeyer \& H. Rieser (eds.). Words, Worlds, and Contexts: New Approaches in Word Semantics. de Gruyter. 38-74.

Kratzer, A. (1991). > Modality=. In A. von Stechow \& D. Wunderlich (eds.) Semantik/Semantics: An International Handbook of Contemporary Research. Berlin: de Gruyter. 639-650.

Krifka, M. (1995). > The Semantics and Pragmatics of Polarity Items=. Linguistic Analysis 25. 209257.

Lee, Y. \& L. Horn (1994). >Any as Indefinite plus Even=. Manuscript. Yale University.

Lewis, D. (1973). Counterfactuals. Cambridge: Harvard University Press.

Lewis, D. (1981). >Ordering Semantics and Premise Semantics for Counterfactuals=. Journal of Philosophical Logic 10. 317-234.

Lewis, D. (1986). Philosophical Papers. Vol. II. Oxford University Press.

Linebarger, M. (1987). >Negative Polarity and Grammatical Representation=. Linguistic and Philosophy 10. 325-387.

Panzeri, F. (2002). Mood and Assertion. PhD dissertation. Universita degli Studi di Milano.

Panzeri, F. (2003). In the (Indicative or Subjunctive) Mood. In M. Weisgerber (ed.) Proceedings of the Conference Asub7- Sinn und Bedeutunge. Arbeitspapier Nr. 114, FB Sprachwissenschaften, Universität Konstanz, Germany. 216-227.

Partee, B. (1991). > Topic, Focus and Quantification=. In S. Moore \& A. Z. Wyner (eds.) Proceedings of Semantic and Linguistic Theory I. Ithaca, NY: Cornell University Press. 159-189.

Partee, B.(1993). $>$ On the $>$ Scope of Negation= and Polarity Sensitivity=. In Eva Haji $\rightleftharpoons$ ová (ed.)

Functional Description of Language. Prague: Faculty of Mathematics and Physics, Charles University. 179-196.

Portner, P. (1992). Situation Theory and the Semantics of Propositional Expressions. PhD dissertation. University of Massachusetts at Amherst.

Portner, P. (1997). > The Semantics of Mood, Complementation, and Conversational Force=. Natural Language Semantics 5.167-212

Portner, P. (1999). > The Semantics of Mood=. Glot International 4. 3-9 
Portner, P. (2003). > The Semantics of Mood=. In L. Cheng \& R. Sybesman (eds.) The Second Glot International State-of-the-Article Book. Berlin: Mouton de Gruyter.47-77.

Portner, P. (2004). > The semantics of imperatives within a theory of clause types.= In K. Watanabe \& R. Young (eds.). Proceedings of semantics and linguistic theory 14. CLC publications, Cornell University.

Portner, P. (2007). >Imperatives and Modals=. Natural Language Semantics 15,4. 351-383.

Quer, J. (1998). Mood at the Interface. Ph.D. dissertation. Universiteit Utrecht, the Netherlands.

Quer, J. (2001). >Interpreting Mood=. Probus 13.81-111.

Ridruejo, E. (1999). > Modo y Modalidad. El modo en las subordinadas sustantivas=. In Ignacio Bosque \& Violeta Demonte (eds.) Gramática descriptiva de la lengua española. Madrid: Espasa. 3207-3251.

Rooth, M. (1985). Association with Focus. PhD Dissertation. University of Massachusetts at Amherst. Rooth, M. (1992). >A Theory of Focus Interpretation=. Natural Language Semantics 1. 75-116.

Schlenker, P. (2005). > The Lazy Frenchman=s Approach to the Subjunctive: Speculations on reference to Worlds and Semantic Defaults in the Analysis of Mood=. In T. Geerts, I. van Gynneken \& H. Jakobs (eds.) Romance Languages and Linguistic Theory 2003. Amsterdam/Philadelphia: John Benjamins.269-309.

Seuren, P. (1973). > The comparative=. In F. Kiefer and N. Ruwet (eds.) Generative Grammar in Europe. Dordrecht: Reidel. 528-564.

Sloman, A. (1970). >Ought and Better=. Mind 79. 385-394.

Stalnaker, R. (1968). >A Theory of Conditionals=. In N. Rescher (ed.) Studies in Logical Theory, American Philosophical Quarterly. Monograph: 2. Oxford: Basil Blackwell. 98-112.

Stalnaker, R. (1984). Inquiry. Cambridge, MA: MIT Press.

Stechow, A. von (1984a). >Comparing Semantic Theories of Comparison=. Journal of Semantics 3. $1-77$.

Stechow, A. von (1984b). =My reaction to Cresswell=s, Hellan=s, Hoeksema $=\mathrm{s}$ and Seuren=s comments=. Journal of Semantics 3. 183-199.

Stechow, A. von (2007). $>$ Times as Degrees $=$.

Terrell, T. D. \& J. Hooper (1974). >A semantically based analysis of Mood in Spanish=. Hispania 57. 484-494. 
Villalta, E. (2006). Context Dependence in the Interpretation of Questions and Subjunctives. $\mathrm{PhD}$ dissertation. Universität Tübingen.

Westerståhl, D. (1985). > Determiners and Context sets=. In G. Van Benthem \& A. Ter Meulen (eds.) Generalized Quantifiers in Natural Language. 45-72.

Wright, G.H. von (1963). >Practical Inference=. The Philosophical Review 72.159-179.

\section{APPENDIX}

In this appendix, a few examples for each predicate class are provided and their behavior with respect to focus sensitivity and degree modification (of intensity) is summarized

\section{A. PREDICATES THAT SELECT THE INDICATIVE MOOD}

\begin{tabular}{|c|c|c|c|c|}
\hline Focus-ser & ivity & $\begin{array}{l}\text { Modification with } \\
\text { enormemente }\end{array}$ & $\begin{array}{l}\text { Modification with } \\
\text { mucho(intensity) }\end{array}$ & $\begin{array}{l}\text { overt comparative } \\
\text { construction possible } \\
\text { (intensity) }\end{array}$ \\
\hline $\begin{array}{l}\text { EPISTEMIC } \\
\text { PREDICATES }\end{array}$ & & & & \\
\hline saber $(>$ know $=)$ & * & * & * & * \\
\hline pensar $(>$ think $=)$ & $*$ & * & $*$ & $*$ \\
\hline $\operatorname{creer}(>$ believe $=)$ & * & $\mathrm{Y}$ & $\mathrm{Y}$ & * \\
\hline $\begin{array}{l}\text { PREDICATES } \\
\text { OF CERTAINTY }\end{array}$ & & & & \\
\hline $\begin{array}{l}\text { estar convencido } \\
(>\text { be convinced }=)\end{array}$ & $*$ & $Y$ & $\mathrm{Y}$ & $*$ \\
\hline $\begin{array}{l}\text { estar seguro } \\
(>\text { be certain }=)\end{array}$ & * & $\mathrm{Y}$ & $\mathrm{Y}$ & * \\
\hline $\begin{array}{l}\text { es cierto } \\
\text { (>it is a matter of fact }=\text { ) }\end{array}$ & * & * & $\mathrm{Y}$ & $*$ \\
\hline es claro $(>$ it is clear $=$ ) & $*$ & $*$ & $\mathrm{Y}$ & $*$ \\
\hline es obvio (>it is obvious $=$ ) & $*$ & * & $\mathrm{Y}$ & * \\
\hline $\begin{array}{l}\text { PREDICATES } \\
\text { OF } \\
\text { COMMUNICATI }\end{array}$ & & & & \\
\hline
\end{tabular}




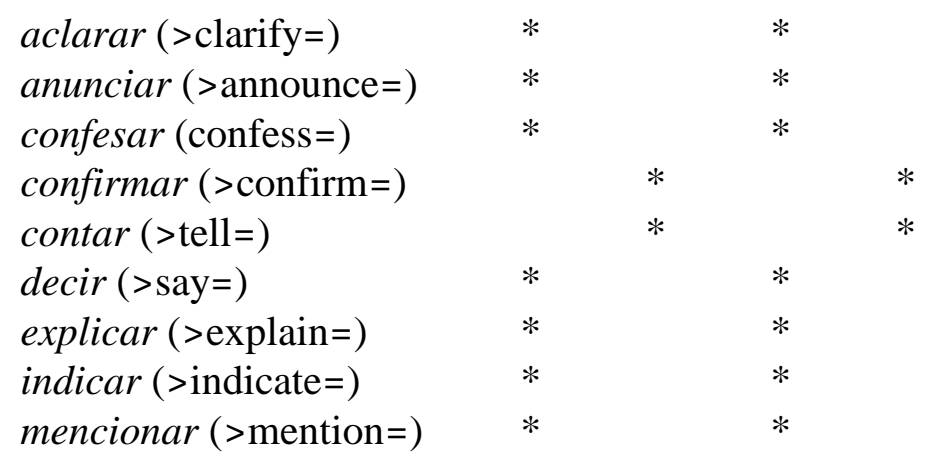

\section{Focus-sensitivity Modification with enormemente}

COMMISSIVES

prometer $(>$ promise $=)$

ofrecer $(>$ offer $=)$

proponer $(>$ propose $=)$

FICTION VERBS

soñar $(>$ dream $=)$

imaginar $(>$ imagine $=)$

PREDICATES OF

MENTAL JUDGEMENT

acordarse (>remember $=) \quad *$

adivinar $(>$ guess $=) \quad *$

anticipar $(>$ anticipate $=) \quad *$

comprender (>understand=) *

darse cuenta $(>$ realize $=) \quad *$

descubrir (>discover $=) \quad *$

estar de acuerdo (>agree=) *

sospechar $(>$ suspect $=)$

suponer $(>$ suppose $=)$

PREDICATES

OF PERCEPTION

notar $(>$ notice $=)$

sentir $(>$ feel $=)$

$\operatorname{ver}(>$ see $=)$ *
* $*$

* *

* *

* *

* *

* *

* *

* *

* $\quad *$

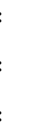

Modification with overt comparative mucho(intensity) construction possible (intensity)

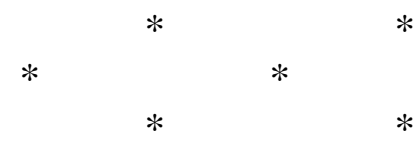

* $*$ $*$

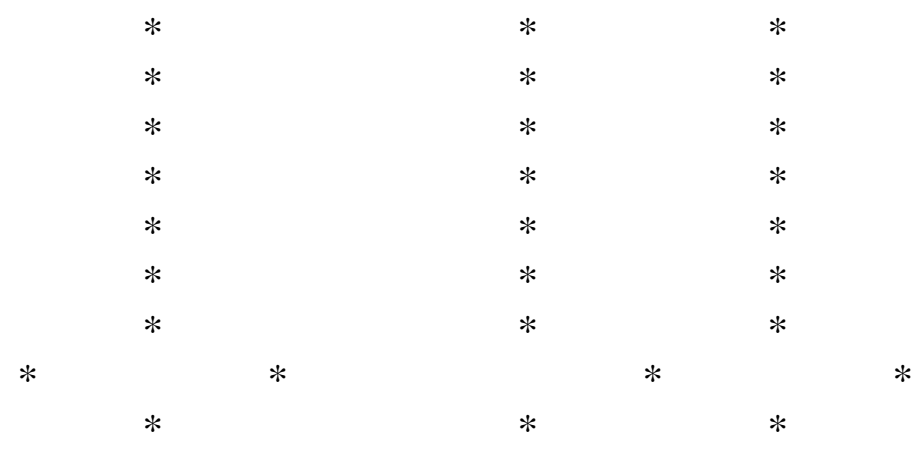

* *


entender $(>$ hear $=)$ 


\section{B. PREDICATES THAT SELECT THE SUBJUNCTIVE MOOD}

\author{
Focus-sensitivity \\ Modification with \\ enormemente
}

Modification with mucho/muy (intensity) overt comparative construction possible (intensity)

DESIRE

PREDICATES

esperar $(>$ hope $=) \quad \mathrm{Y}$

desear $(>$ desire $=) \quad \mathrm{Y}$

preferir $(>$ prefer $=) \quad \mathrm{Y}$

temer $(>$ fear $=) \quad \mathrm{Y}$

EMOTIVE FACTIVE

PREDICATES

admirar $(>$ admire $=) \quad \mathrm{Y}$

aburrir (>be bored=) $\mathrm{Y}$

alegrar $(>$ be glad $=) \quad \mathrm{Y}$

$\operatorname{aceptar}(>\operatorname{accept}=) \quad \mathrm{Y}$

fascinar $(>$ fascinate $=) \mathrm{Y}$

gustar $(>$ like $=)$

importar $(>$ care $=) \quad \mathrm{Y}$

interesar $(>$ interest $=) \mathrm{Y}$

es estupendo

(>it is great=)

es extraordinario $\quad \mathrm{Y}$

( $>$ it is extraordinary $=$ )

es fabuloso

(>it is fabulous $=$ ) $\quad \mathrm{Y}$

es fantastico

( $>$ it is fantastic $=$ ) $\quad \mathrm{Y}$

es justo (>it is fair) $\mathrm{Y}$

lamentar (>regret=) $\mathrm{Y}$

es lógico

(>it is logic $=$ ) $\quad \mathrm{Y}$

es natural

(>it is natural=) $\quad \mathrm{Y}$

es normal

(>it is normal=) $\quad \mathrm{Y}$

es peligroso

$(>$ it is dangerous $=$ ) $\quad \mathrm{Y}$
Y

$\mathrm{Y}$

Y

Y

$\begin{array}{ll}\mathrm{Y} & \mathrm{Y} \\ \mathrm{Y} & \mathrm{Y} \\ \mathrm{Y} & \mathrm{Y} \\ \mathrm{Y} & \mathrm{Y}\end{array}$

Y

Y

$\begin{array}{ccc}\mathrm{Y} & & \mathrm{Y} \\ \mathrm{Y} & & \mathrm{Y} \\ \mathrm{Y} & & \mathrm{Y} \\ & & \mathrm{Y} \\ \mathrm{Y} & & \mathrm{Y} \\ & \mathrm{Y} & \end{array}$

Y

$\mathrm{Y}$

Y

Y

Y

Y

*

Y

Y

*

Y

Y

Y

?

*

Y

Y

$\mathrm{Y} \quad \mathrm{Y}$

*

Y

Y

*

Y

Y

$*$

Y

Y

Y$$
?
$$$$
?
$$

Y

$\mathrm{Y}$

$\mathrm{Y}$

$\mathrm{Y}$

Y

Y

Y

Y

Y

Y




\section{Focus-sensitivity Modification with enormemente}

preocupar

( $>$ be worried $=$ )

Y

Y

es raro

(>it is strange $=$ ) $\quad \mathrm{Y}$

quejar

(>complain $=$ )

sentir

(>be sorry $=$ )

sorprender

(>be surprised $=$ ) $\quad \mathrm{Y}$

es útil

( $>$ it is useful=)

es urgente

( $>$ it is urgent $=$ )

Y

$\mathrm{Y}$

Y

Y

Y

Y

Y

$\mathrm{Y}$

$\mathrm{Y}$

Y

Y

Y
Modification with mucho/muy (intensity) overt comparative construction possible (intensity)

Y

$\mathrm{Y}$

Y

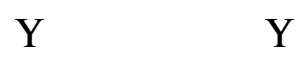

$\begin{array}{ll}\text { Y } & Y\end{array}$

Y

Y

Y

$\mathrm{Y}$

Y

MODAL

PREDICATES

es posible $\quad \mathrm{Y}$

Y

Y

Y

( $>$ it is possible $=$ )

es necesario

Y

Y

Y

Y

Y

Y

Y

(>it is likely=)

necesitar

Y

Y

Y

Y

(>need $=$ )

DIRECTIVE PREDICATES

autorizar $(>$ authorize $=) \mathrm{Y}$

aconsejar (>advise $=)$ Y

animar (>encourage $=)$

Y

$\mathrm{Y}$

exigir $(>$ request $=) \quad \mathrm{Y}$

invitar $a(>$ invite $=) \quad \mathrm{Y}$

impedir (>hinder $=) \quad \mathrm{Y}$

mandar (>order $=) \quad \mathrm{Y}$

obligar $(>$ oblige $=) \quad \mathrm{Y}$

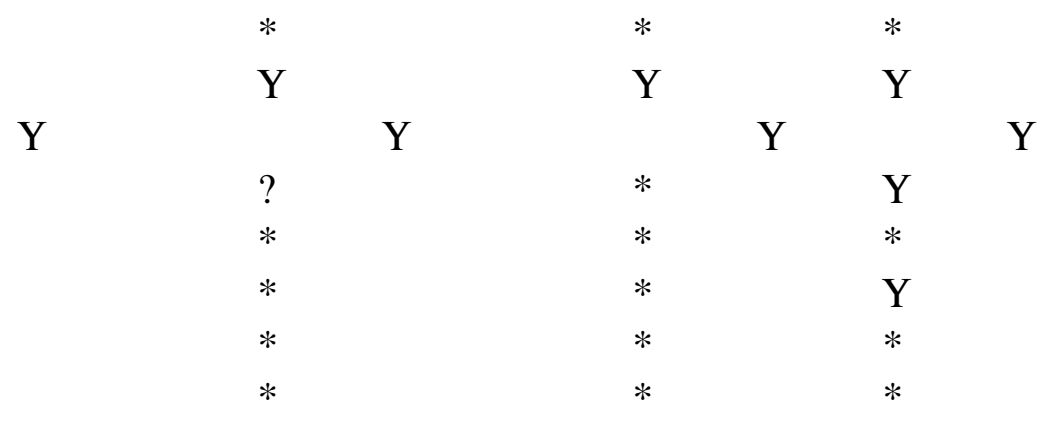


$\begin{array}{ll}\operatorname{ledir}(>\operatorname{ask}=) & \mathrm{Y} \\ \operatorname{prohibir}(>\text { forbid }=) & \mathrm{Y} \\ & \text { Focus-sensitivity }\end{array}$

recomendar

(>recommend $=) \quad \mathrm{Y}$

sugerir $(>$ suggest $=) \quad \mathrm{Y}$

CAUSATIVE PREDICATES

hacer $(>$ make $=) \quad \mathrm{Y}$

conseguir (>achieve=)

lograr (>accomplish=)

evitar (>avoid=) Y

contribuir

(>contribute $=) \quad \mathrm{Y}$

ayudar $a(>$ help $=) \quad \mathrm{Y}$

$\operatorname{causar}(>$ cause $=) \quad \mathrm{Y}$
$\mathrm{Y}$
$\mathrm{Y}$

Modification with

enormemente
Y

$\mathrm{Y}$
Modification with mucho/muy (intensity)
*

*

overt comparative construction possible (intensity)

$\begin{array}{ll}Y & Y \\ Y & Y\end{array}$

\section{Acknowledgments}

Over the years, this paper has benefitted from the help and comments of many, many people . $\mathrm{I}=\mathrm{m}$ especially indebted to Sigrid Beck, Roger Higgins, Angelika Kratzer, Claudia Maienborn, Lisa Matthewson, Barbara Partee, Arnim von Stechow, and Wolfgang Sternefeld, and two anonymous reviewers. I would also like to thank Ana Arregui, Rajesh Bhatt, Nicholas Asher, Jenny Doetjes, Kai von Fintel, Irene Heim, Chris Kennedy, Sveta Krasikova, Doris Penka, Paul Portner, Yael Sharvit, and Philippe Schlenker for many comments and suggestions, as well as the audiences at the SALT X conference at Cornell University, the 30th Symposium of Romance Linguistics at the University of Florida, and the audiences at talks given at the University of Connecticut, at the University of Texas at Austin, at the Université Paris 7, and at the Universität Tübingen. All errors are mine. This paper was written under the support of the SFB 441/B17 project at the Universität Tübingen. 